\title{
Biocompatibility and Surface Characteristics of Resin-Modified Glass Ionomer Cements with Ammonium Quaternary Compounds or Silver Nanoparticles: An In Vitro Study
}

\author{
Silvia Munguía-Moreno $\left(\mathbb{D},{ }^{1}\right.$ Gabriel-Alejandro Martínez-Castañón ${ }^{D},{ }^{1}$ Nuria Patiño-Marín, ${ }^{1}$ \\ Claudio Cabral-Romero $\mathbb{D}^{2}{ }^{2}$ and Norma-Verónica Zavala-Alonso $\mathbb{D}^{1}$ \\ ${ }^{1}$ Doctorate Program in Dental Science, Faculty of Dentistry, Av. Dr. Manuel Nava No. 2 Zona Universitaria, Autonomous University \\ of San Luis Potosí, CP 78290 San Luis Potosí, SLP, Mexico \\ ${ }^{2}$ Faculty of Dentistry, Dr. Eduardo Aguirre Pequeño Sn, Mitras Centro, Autonomous University of Nuevo León, CP 64460 Monterrey, \\ NL, Mexico
}

Correspondence should be addressed to Norma-Verónica Zavala-Alonso; nveroza@fest.uaslp.mx

Received 12 April 2018; Revised 11 July 2018; Accepted 7 August 2018; Published 2 October 2018

Academic Editor: Ilaria Armentano

Copyright (c) 2018 Silvia Munguía-Moreno et al. This is an open access article distributed under the Creative Commons Attribution License, which permits unrestricted use, distribution, and reproduction in any medium, provided the original work is properly cited.

\begin{abstract}
Glass ionomer cements are materials with diverse clinical applications. Its use is indicated in patients with special needs, pediatric patients, and the elderly; accordingly, it is important to know its properties. The aim of the present study was to determine the cytotoxicity, surface roughness, microhardness, and surface characteristics of GC Fuji ORTHO LC and GC Fuji PLUS resin-modified glass ionomer cements (RMGICs) with 1 and $2 \%$ of benzalkonium chloride, cetylpyridinium chloride, hexadecyltrimethylammonium bromide, or silver nanoparticles. All the experimental groups increase or decrease statistically significantly the VHN $(P<0.05)$ compared with the control group, except for GC Fuji PLUS added with hexadecyltrimethylammonium bromide $1 \mathrm{wt} \%$. In the same way, all groups show a statistically significant $(P<0.05)$ increase or decrease in Ra compared with the control group except for GC Fuji ORTHO added with benzalkonium chloride 2 wt\%, GC Fuji PLUS added with benzalkonium chloride $2 \mathrm{wt} \%$, and GC Fuji PLUS added with cetylpyridinium chloride $2 \mathrm{wt} \%$. The SEM micrographs show similar surface images between the control and experimental groups. When a dental material is modified, it is important to reevaluate its biological and mechanical characteristics. In the present study, all the additions modified the cytotoxicity and surface characteristics of RMGICs, by increasing or decreasing these properties.
\end{abstract}

\section{Introduction}

In clinical practice, the dentist has a series of materials among which he must choose the best option for each treatment. Regarding the cementation materials, there is a wide variety; currently, the most commonly used are glass ionomer cements (GICs) and resin composites. These two materials are different in their chemical composition; the GICs are formed by calcium fluoroaluminum silicate glass powder and polyacrylic acid, whilst the resin composites consist of resin monomers that in contact with an initiator form chains of resin polymers. Their clinical indications are also different, since the resin composites require a longer operative time to be placed as they must be placed in thin layers, as well as a specific care so that they are not in contact with the moisture present in the mouth [1].

GICs are materials whose use is indicated for the treatment of patients with special needs, pediatric patients, and elderly patients. This is because these materials provide the clinician advantages such as shorter working time than resins, an important aspect since sometimes these patients suffer anxiety or fear when going to the dental office and they must work in short sessions with them. Furthermore, it has been reported that its use is appropriate to avoid caries secondary to cementation and it has remineralization properties, which is important because some of these patients have 
limited access to dental care services and it is necessary to use materials that will have greater operative success [2-6].

Wilson and Kent in the late 1960s introduced the glass ionomer cements (GICs) at the Laboratory of the Government Chemist, London [7]. The resin-modified glass ionomer materials are hybrid materials of traditional glass ionomer cement with a small addition of light-curing resin and hence exhibit intermediate properties of both, with some characteristics superior to conventional glass ionomer materials. These materials have some properties like adhesion to tooth structure and base metals, release of fluoride, thermal compatibility with tooth structure, and biocompatibility [8]. Resin-modified glass ionomer cements (RMGICs) have multiple clinical applications including restorations, lining and base, core build-up, and luting [9].

To improve the antibacterial efficacy of GICs, antibacterial substances such as chlorhexidine [10-12], zinc oxide [13], doxycycline hyclate [14], quaternary ammonium compounds, benzalkonium chloride, cetylpyridinium chloride, hexadecyltrimethylammonium bromide, quaternary ammonium polyethyleneimine nanoparticles [15-18], and silver nanoparticles were used [19]. These studies reported acceptable results in the antibacterial effect. Quaternary ammonium compounds (QAC) are cationic compounds that possess a basic structure $\left(\mathrm{NH}_{4}^{+}\right)$. The QAC penetrate the bacteria cell wall, react with the cytoplasmic membrane, and induce wall lysis caused by autolytic enzymes. These compounds are used as disinfectants, antiseptics, pharmaceutical products, and cosmetics [20]. Some quaternary ammonium compounds in dental materials have been studied and include the incorporation of methacryloxylethylcetyl ammonium chloride in bonding agents [21, 22], the incorporation of methacryloyloxydodecyl pyridinium bromide and quaternary ammonium polyethyleneimine nanoparticles into composite resins [23-25], and the incorporation of poly-quaternary ammonium-dyed salt glass ionomer cements. These studies found that the materials with quaternary ammonium compound have significant antibacterial activity [26]. In the present study, the incorporation of benzalkonium chloride, cetylpyridinium chloride, or hexadecyltrimethylammonium bromide to conventional glass ionomer cements has been found to have significant bactericidal effect against Streptococcus mutans, Lactobacillus casei, Streptococcus salivarius, Lactobacillus acidophilus, Actinomyces odontolyticus, Actinomyces naeslundii, and Enterococcus faecalis [27].

The silver nanoparticles are insoluble clusters of silver atoms measuring less than $100 \mathrm{~nm}$. The nanoparticles penetrate in the bacteria and get attached in the bacterial membrane. Studies indicated that silver interacts with sulfhydryl groups of proteins and with DNA, altering hydrogen bonding, respiratory chain, cell division, cell wall synthesis, and unwinding finally leading to cell death [28]. Recent studies have investigated the possibility of incorporating silver nanoparticles into bonding agents to improve their antibacterial properties [29-31]. It has been found that the incorporation of silver nanoparticles has a significant bactericidal effect against Streptococcus mutans, Candida albicans, Enterococcus faecalis, Staphylococcus aureus, and
Porphyromonas aeruginosa; therefore, it is proposed to incorporate them into glass ionomer cements [32].

The potential toxic effect of antibacterial substances should be investigated. Few studies have evaluated the effect of quaternary ammonium compounds and silver nanoparticles on the cytotoxicity of glass ionomers. The physical properties of RMGICs may be altered by the addition of antibacterial compounds, and it is important to evaluate some main characteristics. Hardness is the resistance of a material to indentation or penetration, and it has been used to predict the wear resistance of a material against applied forces such as occlusal forces [33]. On the other side, the surface roughness of the RMGICs is related to its ability to retain dental plaque [16].

This study evaluated the cytotoxicity, microhardness (VHN), surface roughness (Ra), and surface morphology of RMGICs with the addition of benzalkonium chloride (BC), cetylpyridinium chloride (DP), hexadecyltrimethylammonium bromide (CE), or silver nanoparticles (AgNP).

\section{Materials and Methods}

2.1. Sampler Preparation. The luting resin-modified glass ionomer (RMGIC) GC Fuji PLUS and GC Fuji ORTHO LC (GC Corporation, Tokyo, Japan) were chosen as controls for the present study. Sixteen experimental groups were made by adding BC, DP, and CE (Sigma-Aldrich, Steinheim Germany) at $1 \mathrm{wt} \%$ and $2 \mathrm{wt} \%$ into the powder of the RMGIC and AgNP synthesis previously reported [34] at $1 \mathrm{wt} \%$ and $2 \mathrm{wt} \%$ into the liquid of the RMGIC.

Nine specimens of each group were prepared for cytotoxicity test measuring $5 \mathrm{~mm}$ in diameter and $2 \mathrm{~mm}$ length, 25 specimens for microhardness and surface roughness measuring $5 \mathrm{~mm}$ in diameter and $2 \mathrm{~mm}$ length, and one for scanning electronic microscopy measuring $5 \mathrm{~mm}$ in diameter and $2 \mathrm{~mm}$ length, per the manufacturer's instructions, in standard cylindrical Teflon molds. Specimens were prepared between cellophane strips and glass slabs and light curing if needed with a LED.B (Woodpecker Medical Instrument Co., Ltd., Guilin, China). The specimens for the microhardness test, surface roughness, and scanning electron microscopy were stored at $37^{\circ} \mathrm{C}$ in distilled water and in dry conditions for $24 \mathrm{hr}$. The specimens that were stored in dry conditions showed cracks on the surface that prevented them from performing the tests; Figure 1 shows the surface of the control materials observed with scanning electron microscopy to an amplification of $\times 50$. All specimens used in the cytotoxicity test were sterilized with UV radiation for $40 \mathrm{~min}$ on each side and immersed in $200 \mu \mathrm{l}$ of minimum essential medium (MEM) for $24 \mathrm{~h}$ at $37^{\circ} \mathrm{C}$ [35]. The $\mathrm{pH}$ of the medium of 3 specimens per group was recorded before being in contact with the samples and after 24 hours of incubation with the samples.

The cytotoxic effect of RMGIC GC Fuji PLUS and GC Fuji Ortho LC was evaluated on epithelial cells.

2.2. Cytotoxicity Testing. African green monkey kidney epithelial cells (strain MA104) were cultured in MEM supplemented with $3 \%$ of fetal bovine serum (FBS, Biowest, 


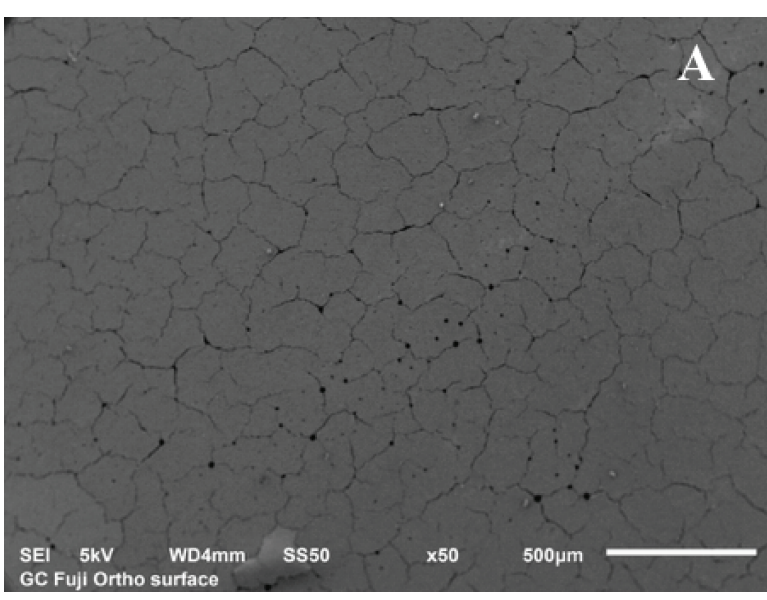

(a)

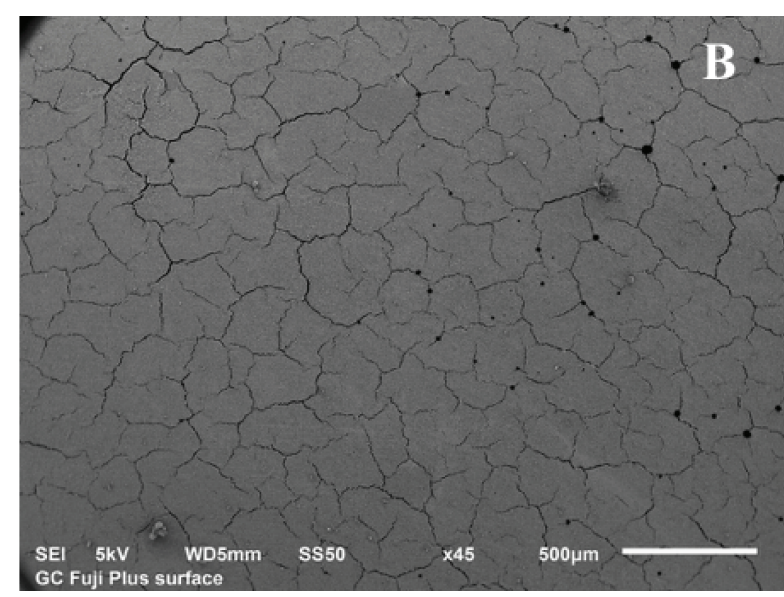

(b)

FIGURE 1: Scanning electron microscopy micrographs at $\times 50$ of the specimens stored in dry conditions: (a) GC Fuji Ortho LC and (b) GC Fuji PLUS.

TABle 1: $\mathrm{pH}$ variations at $24 \mathrm{hr}$ for GC Fuji ORTHO LC modifications.

\begin{tabular}{lc}
\hline Groups & Mean pH \\
\hline GC Fuji ORTHO LC & 7.1 \\
$\begin{array}{l}\text { GC Fuji ORTHO LC + hexadecyltrimethylammonium } \\
\text { bromide 1\% }\end{array}$ & 7.3 \\
$\begin{array}{l}\text { GC Fuji ORTHO LC + hexadecyltrimethylammonium } \\
\text { bromide 2\% }\end{array}$ & 7.2 \\
GC Fuji ORTHO LC + benzalkonium chloride 1\% & 7.3 \\
GC Fuji ORTHO LC + benzalkonium chloride 2\% & 7.1 \\
GC Fuji ORTHO LC + cetylpyridinium chloride 1\% & 7.5 \\
GC Fuji ORTHO LC + cetylpyridinium chloride 2\% & 7.3 \\
GC Fuji ORTHO LC + silver nanoparticles 1\% & 7.3 \\
GC Fuji ORTHO LC + silver nanoparticles 2\% & 7.2 \\
\hline
\end{tabular}

Nuaillé, France) at $37^{\circ} \mathrm{C}$ with $5 \%$ of $\mathrm{CO}_{2}$, in 96 -well microtiter plates (Thermo Fisher Scientific, MA, USA) for 48 hours until we got a confluent monolayer. After this period, $100 \mu \mathrm{l}$ extract of experimental and control materials was applied to the previously cultured MA104 cells for $24 \mathrm{hr}$. Cultures with MEM were used as the negative control of cytotoxicity.

Nine specimens of each group were used for analysis of cell metabolism by the 3-(4,5-dimethyl-thiazol-2-yl)-2,5diphenyl-tetrazolium bromide (MTT) assay. For the MTT assay, the extracts were aspirated and replaced by $90 \mu \mathrm{l}$ of MEM plus $10 \mu \mathrm{l}$ of MTT solution ( $5 \mathrm{mg} / \mathrm{ml}$ sterile PBS) and incubated at $37^{\circ} \mathrm{C}$ and $5 \% \mathrm{CO} 2$ for $4 \mathrm{hr}$. Then, the culture medium with the MTT solution was aspirated and $100 \mu \mathrm{l}$ DMSO was added to each well to dissolve the formazan crystal resulting from the cleavage of the MTT salt ring by the SDH enzyme present in the mitochondria of viable cells. Cell viability was evaluated by spectrophotometry as being proportional to the absorbance measured at $570 \mathrm{~nm}$ wavelengths with an ELISA microplate reader (model 3550-UV, Bio-Rad Laboratories, Hercules, CA, USA). The values obtained from the experiments were averaged to provide a single value for each material. The means were calculated for the groups
TABLE 2: pH f GC Fuji PLUS modifications.

\begin{tabular}{lc}
\hline Groups & Mean pH \\
\hline GC Fuji PLUS & 7.8 \\
GC Fuji PLUS + hexadecyltrimethylammonium & 7.6 \\
bromide 1\% & \\
GC Fuji PLUS + hexadecyltrimethylammonium & 7.9 \\
bromide 2\% & 7.7 \\
GC Fuji PLUS + benzalkonium chloride 1\% chloride 2\% & 7.5 \\
GC Fuji PLUS + benzalkonium chloride 1\% & 7.8 \\
GC Fuji PLUS + cetylpyridinium chloride 2\% & 8.1 \\
GC Fuji PLUS + cetylpyridinium chlo $\%$ & 7.6 \\
GC Fuji PLUS + silver nanoparticles 1\% & 7.7 \\
GC Fuji PLUS + silver nanoparticles 2\% & \\
\hline
\end{tabular}

and transformed into percentages, which represented the inhibitory effect of the mitochondrial activity of the cells by extracts. The negative control (MEM) was defined as having $100 \%$ cell metabolism [36].

2.3. Confocal Laser Scanning Microscopy (CLSM). Three specimens of each group were used for CLSM. The MA104 cells previously cultured with the RMGIC extracts were stained with calcein acetoxymethylester (Calcein AM, Molecular Probes) and diluted in DMSO for a final concentration of $2 \mu \mathrm{m}$; this fluorescein derivate crosses the cell membrane in an electrically neutral form. The calcein AM is converted by intracellular esterase into de negatively charged fluorescent calcein, and is retained in the intracellular compartment so long as plasma membranes are intact; however, the dye rapidly leaks from the cells with compromised membranes, even in the presence of residual intracellular esterase activity. After $30 \mathrm{~min}$, the images were obtained through a Nikon Plan Apo X60, NA L.4, oil objective [37], and a Nikon camera.

2.4. Microhardness Test. The specimens for the microhardness test were stored at $37^{\circ} \mathrm{C}$ in distilled water for $24 \mathrm{hr}$. Vickers hardness measurements were made with a standard microhardness tester (Micro Vickers Hardness Tester HV- 
TABLE 3: Cell viability percentages by MTT assay for GC Fuji ORTHO LC modifications.

\begin{tabular}{|c|c|c|c|c|}
\hline Groups & Mean & $\mathrm{SD}$ & Maximum & Minimum \\
\hline MEM control & 100 & 0 & 100 & 100 \\
\hline GC Fuji ORTHO LC & 11.16 & 1.94 & 13.75 & 9.62 \\
\hline GC Fuji ORTHO LC + hexadecyltrimethylammonium bromide $1 \%$ & 10.95 & 0.72 & 11.5 & 10 \\
\hline GC Fuji ORTHO LC + hexadecyltrimethylammonium bromide $2 \%$ & 10.37 & 0.75 & 11.37 & 9.75 \\
\hline GC Fuji ORTHO LC + benzalkonium chloride $1 \%$ & 11.25 & 0 & 11.25 & 11.25 \\
\hline GC Fuji ORTHO LC + benzalkonium chloride 2\% & $9.41^{*}$ & 0.488 & 10 & 8.87 \\
\hline GC Fuji ORTHO LC + cetylpyridinium chloride 1\% & 9.66 & 1.19 & 11.25 & 8.75 \\
\hline GC Fuji ORTHO LC + cetylpyridinium chloride 2\% & 10.62 & 0.49 & 11.12 & 10 \\
\hline GC Fuji ORTHO LC + silver nanoparticles $1 \%$ & 10.83 & 1.65 & 12.5 & 8.75 \\
\hline GC Fuji ORTHO LC + silver nanoparticles $2 \%$ & 11.95 & 0.43 & 12.5 & 11.5 \\
\hline
\end{tabular}

SD: standard deviation; MTT assay: 3-(4,5-dimethyl-thiazol-2-yl)-2,5-diphenyl-tetrazolium bromide assay. ${ }^{*}$ Statistically significant differences between GC Fuji ORTHO LC and the experimental group.

TABLE 4: Cell viability percentages by MTT assay for GC Fuji PLUS modifications.

\begin{tabular}{|c|c|c|c|c|}
\hline Groups & Mean & $\mathrm{SD}$ & Maximum & Minimum \\
\hline MEM control & 100 & 0 & 100 & 100 \\
\hline GC Fuji PLUS & 9.83 & 0.17 & 10 & 9.62 \\
\hline GC Fuji PLUS + hexadecyltrimethylammonium bromide 1\% & 9.75 & 0.38 & 10 & 9.25 \\
\hline GC Fuji PLUS + hexadecyltrimethylammonium bromide $2 \%$ & 10.83 & 0.62 & 11.25 & 10 \\
\hline GC Fuji PLUS + benzalkonium chloride $1 \%$ & 9.46 & 0.60 & 10.12 & 8.75 \\
\hline GC Fuji PLUS + benzalkonium chloride $2 \%$ & 10.38 & 0.76 & 11.25 & 9.5 \\
\hline GC Fuji PLUS + cetylpyridinium chloride $1 \%$ & 9.79 & 0.31 & 10 & 9.37 \\
\hline GC Fuji PLUS + cetylpyridinium chloride $2 \%$ & $11.25^{*}$ & 0.00 & 11.25 & 11.25 \\
\hline GC Fuji PLUS LC + silver nanoparticles $1 \%$ & 10.17 & 0.82 & 11.25 & 9.5 \\
\hline GC Fuji PLUS + silver nanoparticles $2 \%$ & $12.33^{*}$ & 1.63 & 14.12 & 10.37 \\
\hline
\end{tabular}

SD: standard deviation; MTT assay: 3-(4,5-dimethyl-thiazol-2-yl)-2,5-diphenyl-tetrazolium bromide assay. * Statistically significant differences between GC Fuji PLUS and the experimental group.

1000 Dongguan Sinowon Precision Instrument Co., Ltd., South District, Dongguan, China). A diamond indenter was used with a load of $300 \mathrm{~g}$ for $15 \mathrm{~s}$. Each sample was submitted to three indentations located $200 \mu \mathrm{m}$ far from each other, and the mean of the VHN was recorded. The diagonal length of the impressions was measured, and the VHN was calculated according to the standard formula $\mathrm{H}=1.854 \mathrm{P} / \mathrm{d}^{2}$.

2.5. Surface Roughness. The Ra specimens were stored in distilled water for $24 \mathrm{hr}$ at $37^{\circ} \mathrm{C}$ before measurements. Atomic force microscopy (AFM) was evaluated in contact mode for measurement of surface roughness. All samples were evaluated at the same scan size $\left(49.5 \times 49.5 \mu \mathrm{m}^{2}\right)$ in triplicate in different areas. These were selected at random, and the mean roughness was obtained for each sample. The evaluations of $\mathrm{Ra}$ were carried out at a scanning rate of $49.5 \mu \mathrm{m} / \mathrm{s}$ by using an AFM (Nanosurf easyScan 2, SPM Electronics, Liestal, Switzerland) in contact mode with the silicon nitride ( $\mathrm{SiN}$ ) probe. The conditions used for the short cantilever contact mode were the following: spring constant, $0.1 \mathrm{~N} / \mathrm{m}$; resonant frequency, $28 \mathrm{kHz}$; length, $225 \mu \mathrm{m}$; mean width, $28 \mu \mathrm{m}$; thickness, $1 \mu \mathrm{m}$; tip height, $14 \mu \mathrm{m}$; and radius, $<10 \mathrm{~nm}$. The Nanosurf easyScan 2 software (Version
1.6) was used to measure the AFM parameters. The feedback gains with a set point of $20 \mathrm{nN}$ were as follows: P-Gain: 10000, I-Gain: 1000, and D-Gain: 0. A calibration grid silicon oxide on silicon material (Nanosurf AG, CH-4410, SPM Electronics, Liestal, Switzerland) with an XY periodicity of $10 \mu \mathrm{m}$ and a $Z$ height of $119 \mathrm{~nm}$ was used for calibration prior to each evaluation session.

2.6. Scanning Electron Microscopy (SEM). The samples were viewed with gold coating under SEM. Observations were made in a scanning electron microscope (SEM) (JSM6510 , JEOL, Tokyo, Japan) at $10 \mathrm{kV}$ at $\times 2000$ and $\times 3500$ of magnification.

\section{Statistical Analysis}

Statistical analysis was carried out using the program JMP SAS software (SAS Institute Inc.) with one-way analysis of variance (ANOVA). Tests of differences of the modifications were analyzed using the Tukey-Kramer test, and a value of $P<.05$ was considered statistically significant for MTT assay, $\mathrm{VHN}$, and Ra. 


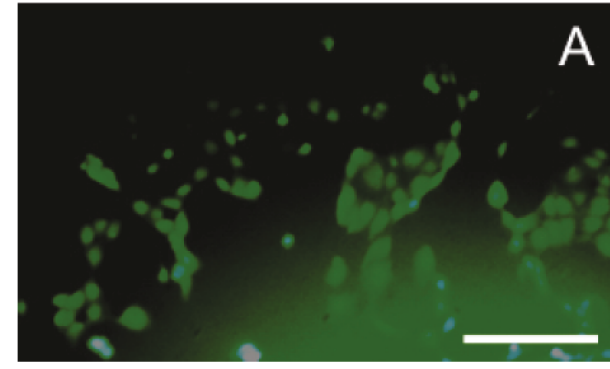

(a)

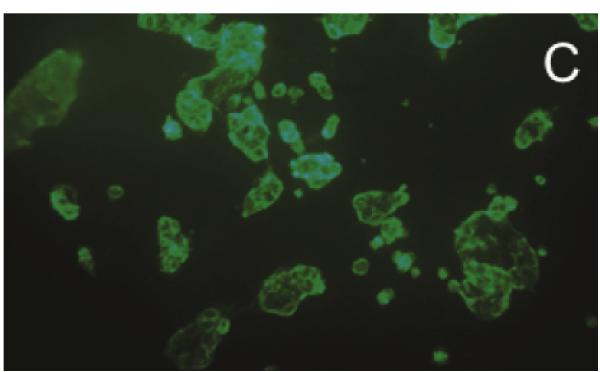

(c)

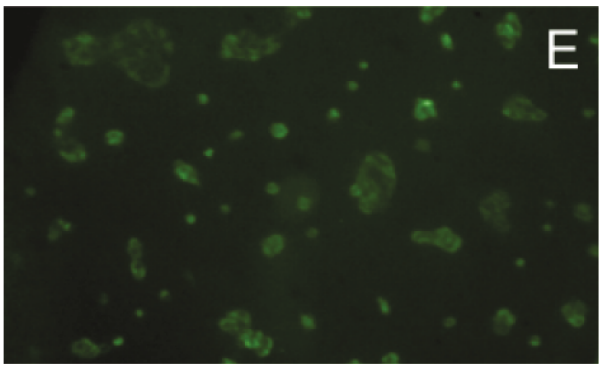

(e)

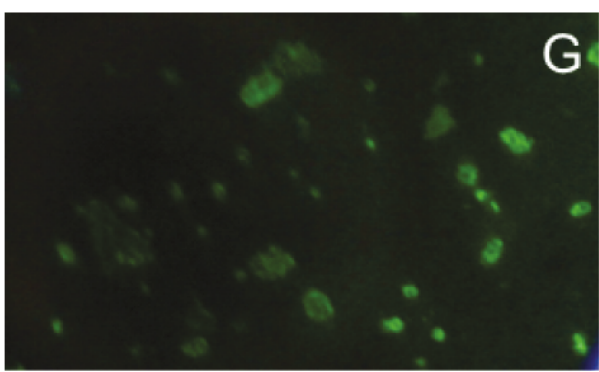

(g)

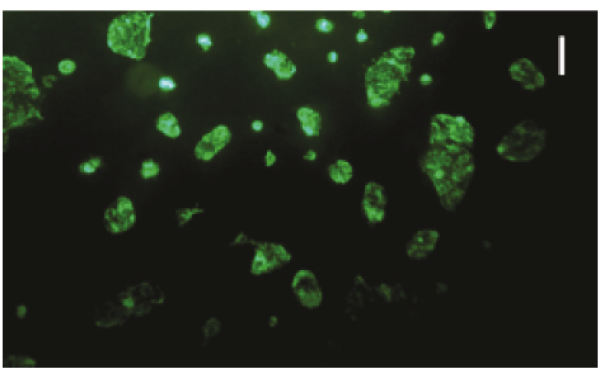

(i)

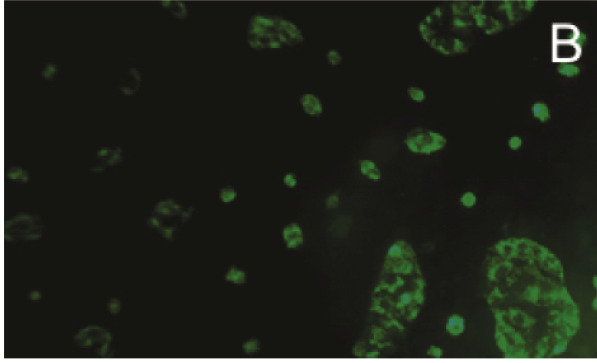

(b)

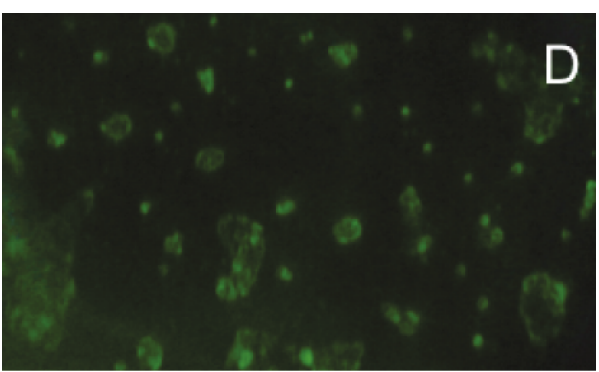

(d)

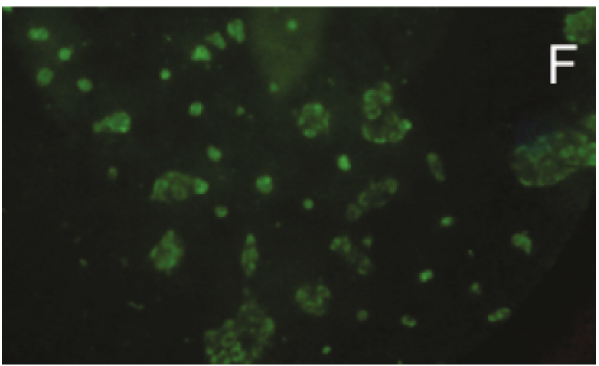

(f)

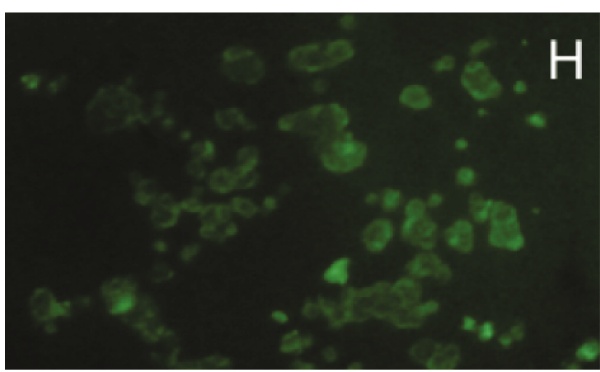

(h)

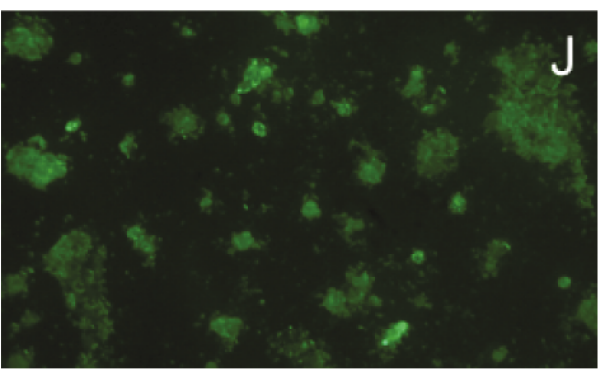

(j)

FIgURE 2: Calcein AM staining of MA104 cells after 24 hr incubation: (a) control with MEM, (b) GC Fuji PLUS, (c) GC Fuji PLUS and hexadecyltrimethylammonium bromide $1 \mathrm{wt} \%$, (d) GC Fuji PLUS and hexadecyltrimethylammonium bromide $2 \mathrm{wt} \%$, (e) GC Fuji PLUS and benzalkonium chloride 1 wt\%, (f) GC Fuji PLUS and benzalkonium chloride 2 wt\%, (g) GC Fuji PLUS and cetylpyridinium chloride $1 \mathrm{wt} \%$, (h) GC Fuji PLUS and cetylpyridinium chloride $2 \mathrm{wt} \%$, (i) GC Fuji PLUS and silver nanoparticles $1 \mathrm{wt} \%$, and (j) GC Fuji PLUS and silver nanoparticles $2 \mathrm{wt} \%$. Scale bar: $50 \mu \mathrm{m}$. 


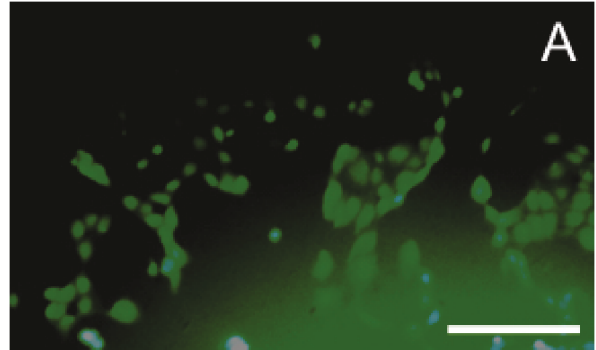

(a)

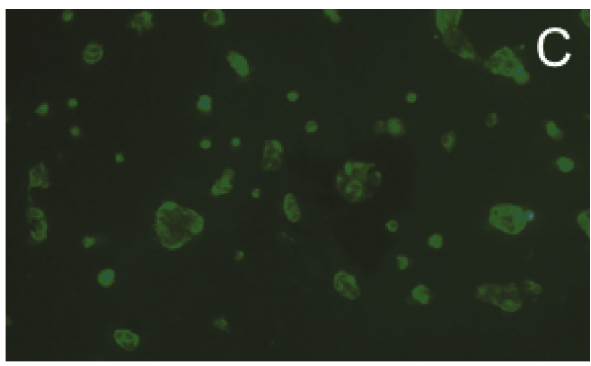

(c)

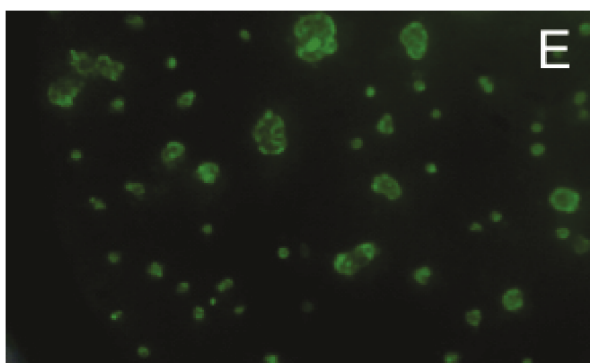

(e)

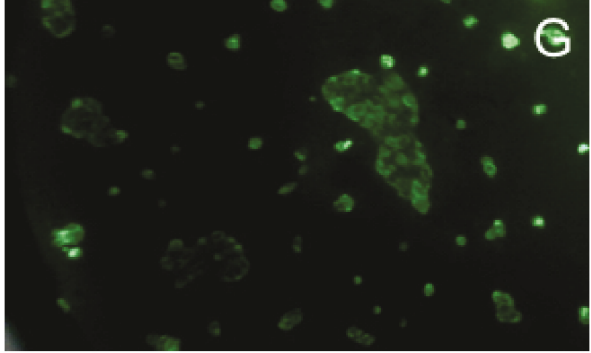

(g)

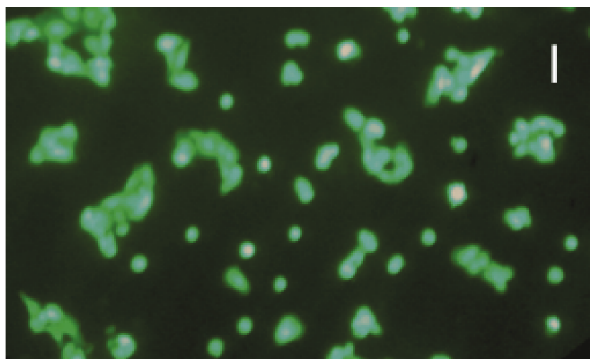

(i)

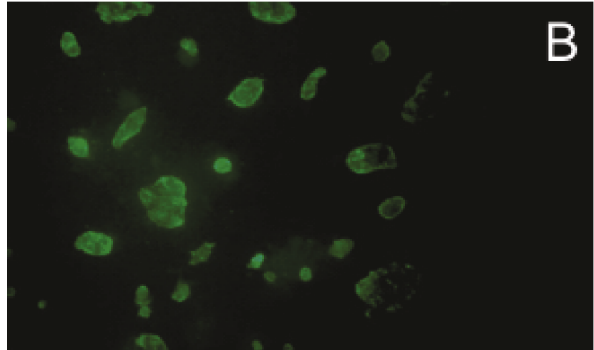

(b)

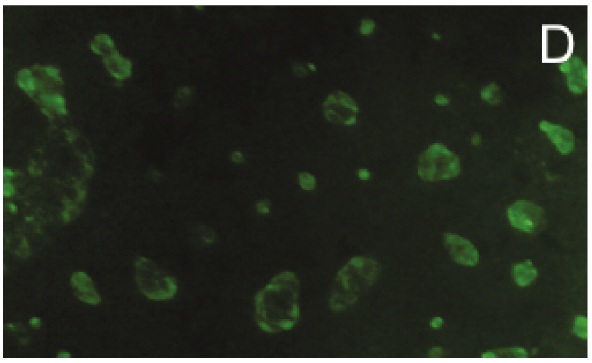

(d)

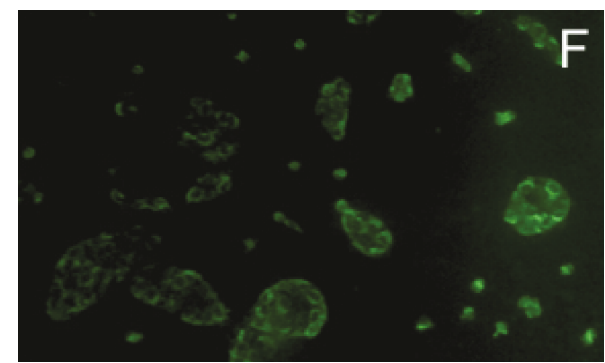

(f)

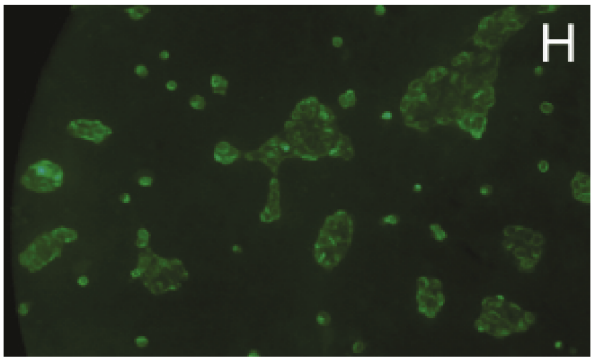

(h)

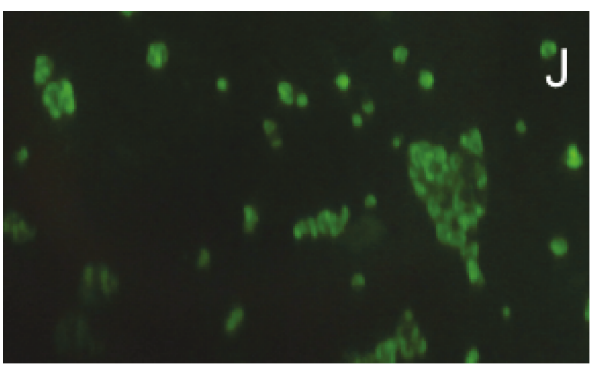

(j)

FIGURE 3: Calcein AM staining of MA104 cells after $24 \mathrm{hr}$ incubation: (a) control with MEM, (b) GC Fuji Ortho LC, (c) GC Fuji Ortho LC and hexadecyltrimethylammonium bromide $1 \mathrm{wt} \%$, (d) GC Fuji Ortho LC and hexadecyltrimethylammonium bromide $2 \mathrm{wt} \%$, (e) GC Fuji Ortho LC and benzalkonium chloride $1 \mathrm{wt} \%$, (f) GC Fuji Ortho LC and benzalkonium chloride $2 \mathrm{wt} \%$, (g) GC Fuji Ortho LC and cetylpyridinium chloride $1 \mathrm{wt} \%$, (h) GC Fuji Ortho LC and cetylpyridinium chloride $2 \mathrm{wt} \%$, (i) GC Fuji Ortho LC and silver nanoparticles $1 \mathrm{wt} \%$, and (j) GC Fuji Ortho LC and silver nanoparticles $2 \mathrm{wt} \%$. Scale bar: $50 \mu \mathrm{m}$. 
TABLE 5: Mean Vickers microhardness and surface roughness \pm SD for GC Fuji ORTHO LC modifications.

\begin{tabular}{lcc}
\hline Groups & VHN & Ra $(\mu \mathrm{m})$ \\
\hline GC Fuji ORTHO LC & $54.48 \pm 1.36$ & $23.45 \pm 2.31$ \\
GC Fuji ORTHO LC + hexadecyltrimethylammonium bromide 1\% & $50.76 \pm 1.31^{*}$ & $29.25 \pm 1.43^{*}$ \\
GC Fuji ORTHO LC + hexadecyltrimethylammonium bromide 2\% & $45.40 \pm 1.44^{*}$ & $15.09 \pm 2.08^{*}$ \\
GC Fuji ORTHO LC + benzalkonium chloride 1\% & $51.65 \pm 1.27^{*}$ & $21.25 \pm 1.69^{*}$ \\
GC Fuji ORTHO LC + benzalkonium chloride 2\% & $44.48 \pm 1.22^{*}$ & $22.34 \pm 1.68$ \\
GC Fuji ORTHO LC + cetylpyridinium chloride 1\% & $41.03 \pm 1.71^{*}$ & $29.32 \pm 2.80^{*}$ \\
GC Fuji ORTHO LC + cetylpyridinium chloride 2\% & $36.10 \pm 1.22^{*}$ & $17.47 \pm 1.37^{*}$ \\
GC Fuji ORTHO LC + silver nanoparticles 1\% & $50.20 \pm 1.78^{*}$ & $14.76 \pm 1.14^{*}$ \\
GC Fuji ORTHO LC + silver nanoparticles 2\% & $33.45 \pm 1.57^{*}$ & $17.19 \pm 0.95^{*}$ \\
\hline
\end{tabular}

SD: standard deviation; VHN: Vickers microhardness number; Ra: surface roughness. * Statistically significant differences between GC Fuji ORTHO LC and the experimental group.

TABle 6: Mean Vickers microhardness and surface roughness \pm SD for GC Fuji PLUS modifications.

\begin{tabular}{lcc}
\hline Groups & VHN & Ra $(\mu \mathrm{m})$ \\
\hline GC Fuji PLUS & $31.29 \pm 1.24$ & $24.21 \pm 1.25$ \\
GC Fuji PLUS + hexadecyltrimethylammonium bromide 1\% & $34.11 \pm 1.74^{*}$ & $14.07 \pm 1.50^{*}$ \\
GC Fuji PLUS + hexadecyltrimethylammonium bromide 2\% & $32.51 \pm 1.89$ & $20.49 \pm 1.35^{*}$ \\
GC Fuji PLUS + benzalkonium chloride 1\% & $28.32 \pm 1.72^{*}$ & $28.31 \pm 1.45^{*}$ \\
GC Fuji PLUS + benzalkonium chloride 2\% & $24.25 \pm 1.78^{*}$ & $24.07 \pm 1.37$ \\
GC Fuji PLUS + cetylpyridinium chloride 1\% & $24.10 \pm 1.58^{*}$ & $24.18 \pm 1.59^{*}$ \\
GC Fuji PLUS + cetylpyridinium chloride 2\% & $23.34 \pm 1.73^{*}$ & $22.53 \pm 1.75$ \\
GC Fuji PLUS + silver nanoparticles 1\% & $47.23 \pm 1.84^{*}$ & $20.22 \pm 1.09^{*}$ \\
GC Fuji PLUS + silver nanoparticles 2\% & $36.30 \pm 1.87^{*}$ & $17.58 \pm 1.58^{*}$ \\
\hline
\end{tabular}

SD: standard deviation; VHN: Vickers microhardness number; Ra: surface roughness. *Statistically significant differences between GC Fuji PLUS and the experimental group.

\section{Results}

The $\mathrm{pH}$ of the minimum essential medium without being in contact with the samples was 7, after contact with the samples presented the variations observed in Tables 1 and 2 .

4.1. Cytotoxicity Testing. Descriptive data of cell survival rates for each group and comparisons of cell viability percentages between the different modifications of GC Fuji PLUS and GC Fuji ORTHO are given in Tables 3 and 4. All the experimental groups showed a significantly decreased cell survival percentage when compared to the control group $(P<0.05)$. The addition of BC at $2 \%$ in the GC Fuji ORTHO LC reduces in a meaningful way similar to that of the cell viability percentage $(P<0.0112)$. DP and AgNP at $2 \%$ addition to GC Fuji PLUS increase meaningfully the cell viability $(P<0.0019$ and $P<0.0001)$.

4.2. Confocal Laser Scanning Microscopy (CLSM). Figures 2 and 3 show the appearance of the cell cultures stained with calcein AM and calcein acetoxymethylester, including MEM control, control cements, and experimental groups. After treatment with the control cements and experimental group elutes, the fluorescence calcein level in the cytoplasm had declined. The control group shows elongated and spindle-shaped cells. The control and experimental groups display rounded and dead fibroblasts and also increased the intercellular space.

4.3. Vickers Microhardness and Surface Roughness. Mean and standard deviations of VHN and $\mathrm{Ra}$ are shown in Tables 5 and 6. All the experimental groups increase or decrease statistically significantly the VHN $(P<0.05)$ when they are compared with the control group, except GC Fuji PLUS added with CE $1 \mathrm{wt} \%$. In the same way, all groups show a statistically significant $(P<0.05)$ increase or decrease in surface roughness when compared to the control group except for GC Fuji ORTHO added with BC 2 wt\%, GC Fuji PLUS added with BC 2 wt $\%$, and GC Fuji PLUS added with DP 2 wt\%.

4.4. Scanning Electron Microscopy. Figures 4, 5, 6, and 7 present the SEM micrographs obtained in this study; control and experimental groups show very similar surface features. The relatively homogeneous and flat surface of glass ionomer is clearly observed with the presence of pores and air voids in the surface. 


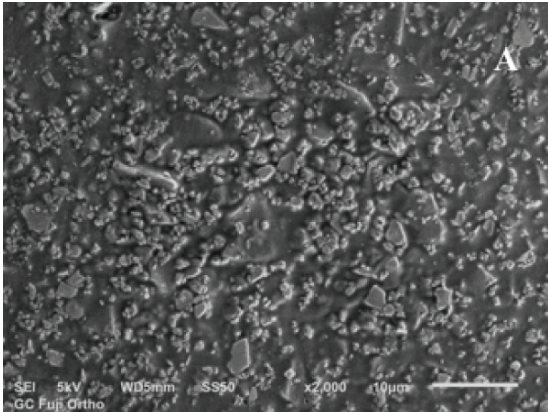

(a)

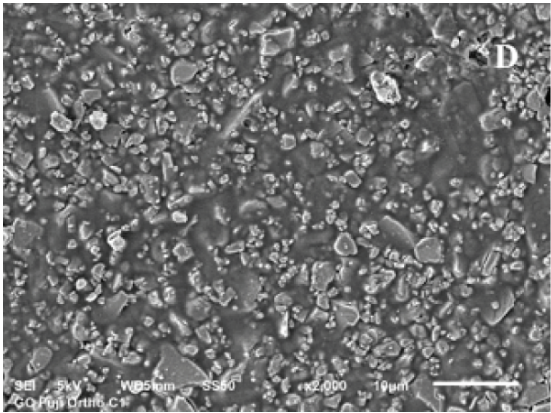

(d)

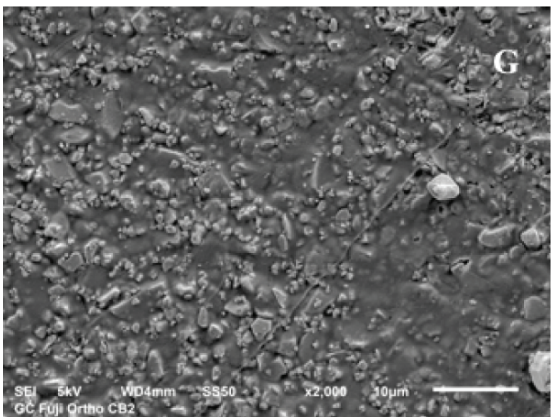

(g)

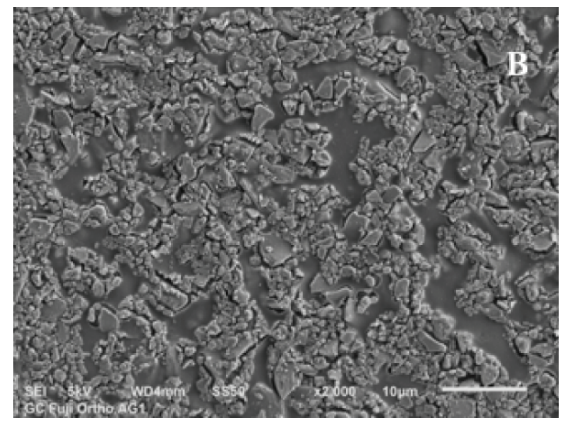

(b)

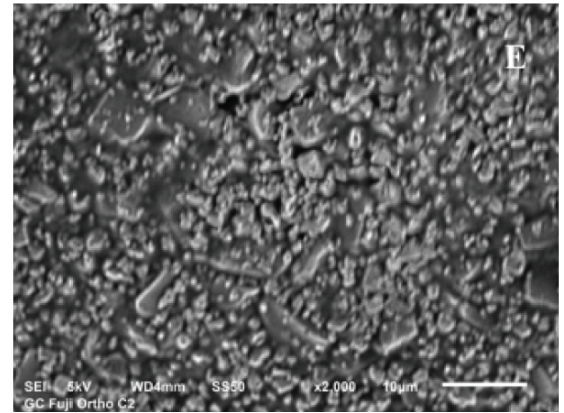

(e)

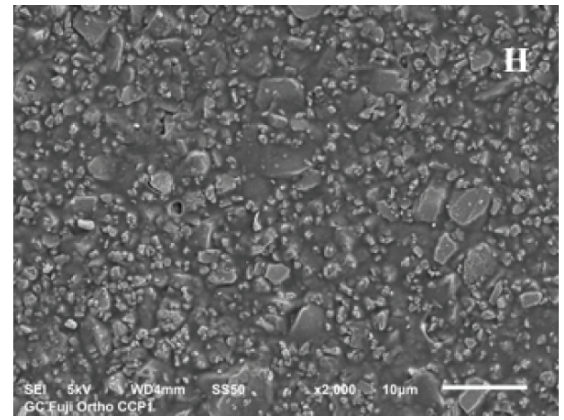

(h)

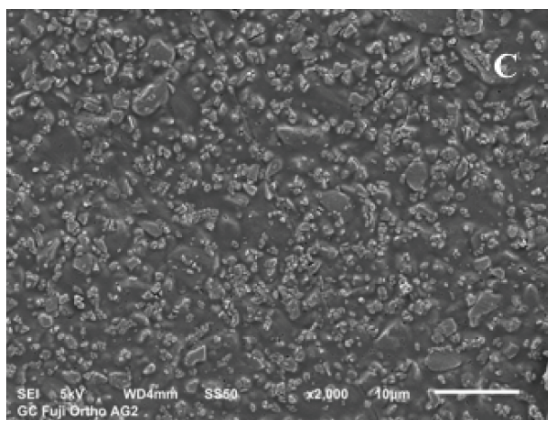

(c)

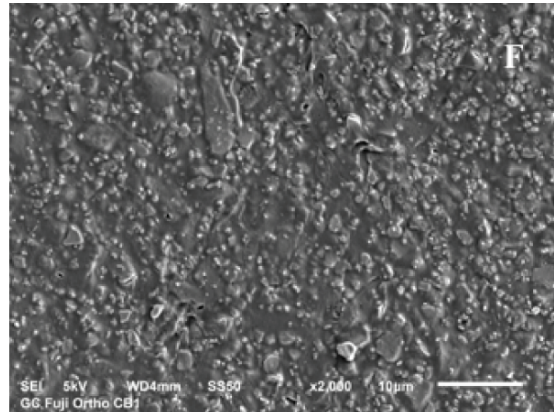

(f)

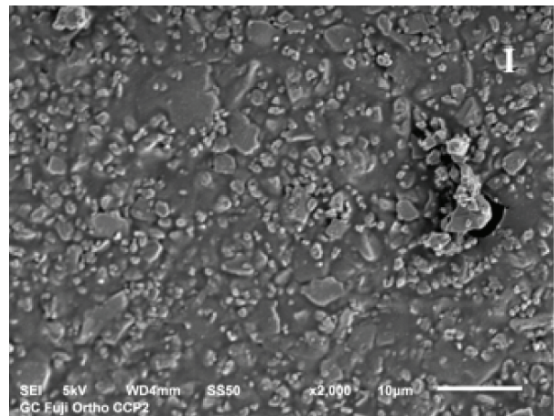

(i)

Figure 4: Scanning electron microscopy micrographs at ×2000: (a) GC Fuji Ortho LC, (b) GC Fuji Ortho LC and silver nanoparticles 1 wt\%, (c) GC Fuji Ortho LC and silver nanoparticles $2 \mathrm{wt} \%$, (d) GC Fuji Ortho LC and hexadecyltrimethylammonium bromide 1 wt\%, (e) GC Fuji Ortho LC and hexadecyltrimethylammonium bromide 2 wt\%, (f) GC Fuji Ortho LC and benzalkonium chloride 1 wt\%, (g) GC Fuji Ortho LC and benzalkonium chloride $2 \mathrm{wt} \%$, (h) GC Fuji Ortho LC and cetylpyridinium chloride $1 \mathrm{wt} \%$, and (i) GC Fuji Ortho LC and cetylpyridinium chloride $2 \mathrm{wt} \%$. Scale bar: $10 \mu \mathrm{m}$.

\section{Discussion}

The in vitro studies can be conducted under controlled conditions and provide a significant amount of information [38]. Different cell lines are used to probe the biocompatibility of dental materials like pulp cells extracted from the maxillary incisors of Sprague Dawley rats, multipotent stromal cells, human foreskin fibroblast, human lung fibroblast, primary human osteoblast, L929 mouse fibroblast, SV40 large T-antigen-transfected bovine dental pulpderived cells, MDPC-23 odontoblast-like cell line, primary pulp fibroblast, and human alveolar osteoblast, for example [39-46]. In this study, the MA-104 epithelial cell line was used because the glass ionomer cements are in direct contact with the epithelial tissue of the oral mucosa. The use of cell lines permits an accurate evaluation of the changes, excluding factors such as age and metabolic and hormonal states of the donor that may influence the cell in primary culture [47]. Different formulations are under development to increase the antibacterial properties of GICs. It is important to determine the biocompatibility properties of new formulations. Adding QAC and silver nanoparticles may alter the in vitro cytotoxicity of GICs. The present in vitro study demonstrated that GC Fuji ORTHO LC and GC Fuji PLUS had higher cytotoxicity in MA104 cells by MTT assay. For the materials with modifications, only the addition of $\mathrm{BC}$ at $2 \%$ in the GC Fuji ORTHO LC reduces the cell viability compared with the control cement without the modification. In part, this is explained because all materials used in the study, both glass ionomers and antimicrobials, have a reported degree of toxicity $[48,49]$. Different in vitro studies assessed the cytotoxicity of GICs and RMGICs on cultured cells 


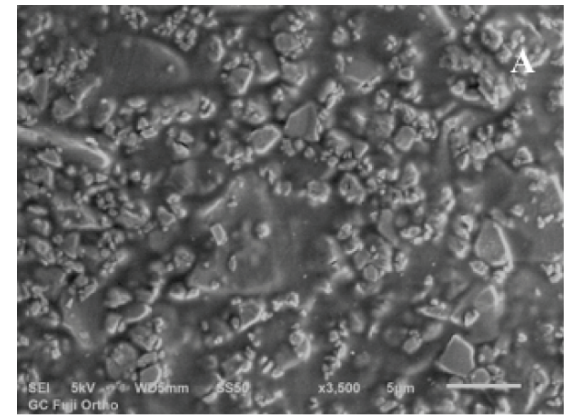

(a)

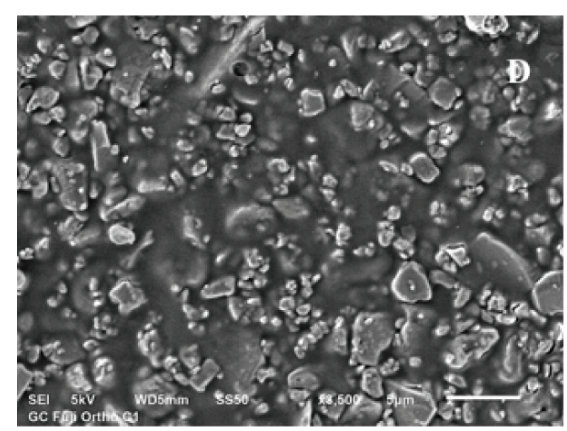

(d)

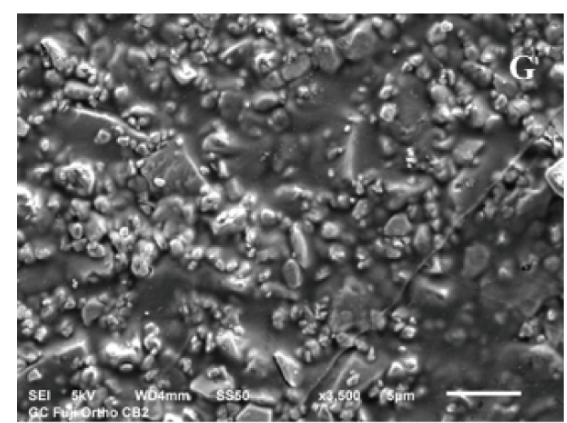

(g)

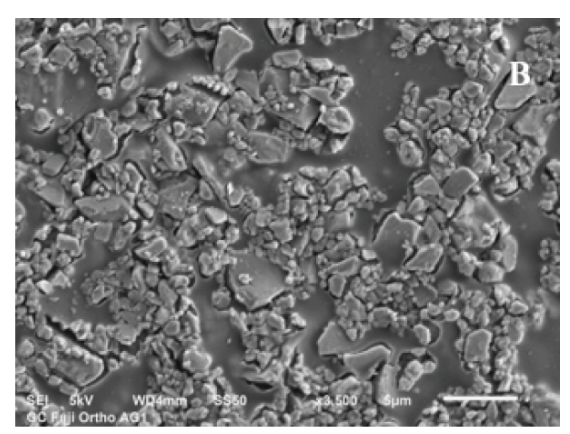

(b)

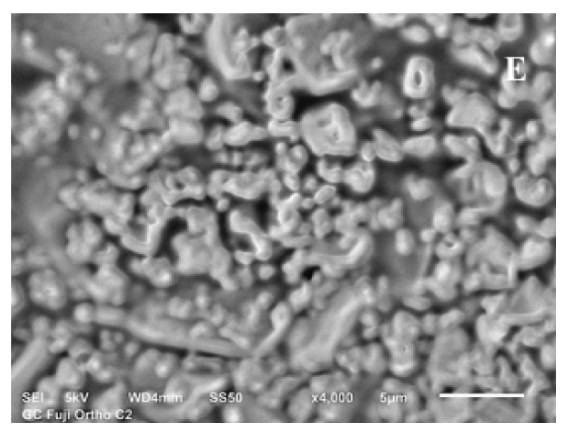

(e)

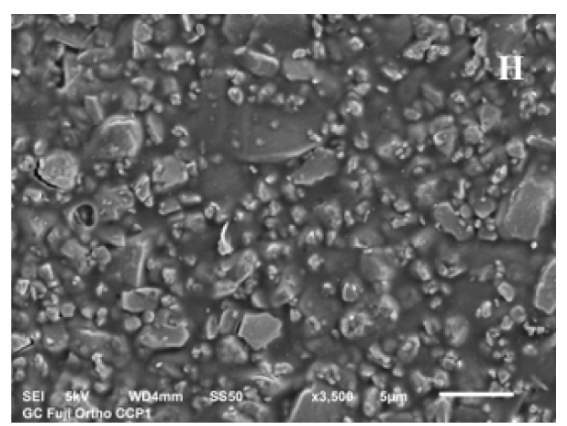

(h)

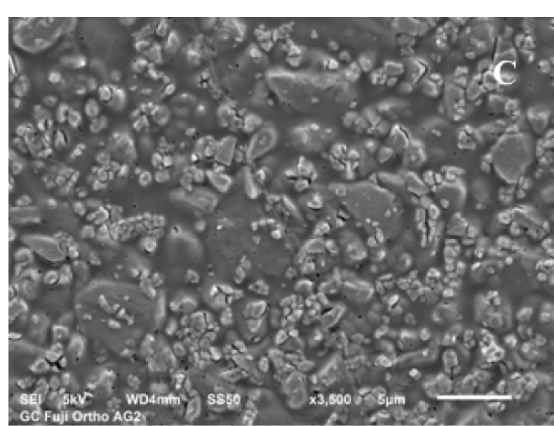

(c)

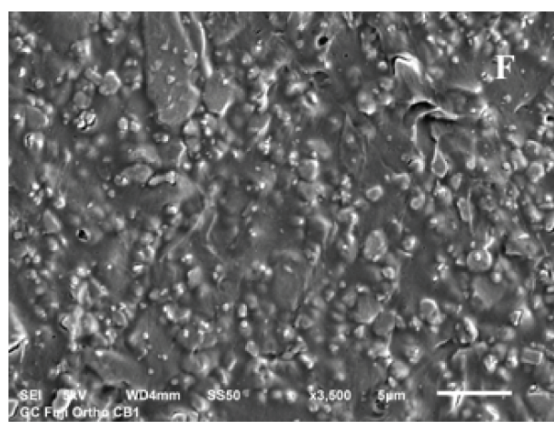

(f)

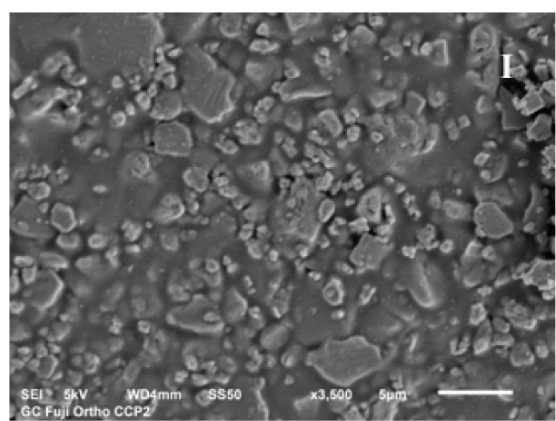

(i)

Figure 5: Scanning electron microscopy micrographs at ×3500: (a) GC Fuji Ortho LC, (b) GC Fuji Ortho LC and silver nanoparticles 1 wt\%, (c) GC Fuji Ortho LC and silver nanoparticles $2 \mathrm{wt} \%$, (d) GC Fuji Ortho LC and hexadecyltrimethylammonium bromide $1 \mathrm{wt} \%$, (e) GC Fuji Ortho LC and hexadecyltrimethylammonium bromide 2 wt\%, (f) GC Fuji Ortho LC and benzalkonium chloride 1 wt\%, (g) GC Fuji Ortho LC and benzalkonium chloride $2 \mathrm{wt} \%$, (h) GC Fuji Ortho LC and cetylpyridinium chloride $1 \mathrm{wt} \%$, and (i) GC Fuji Ortho LC and cetylpyridinium chloride $2 \mathrm{wt} \%$. Scale bar: $5 \mu \mathrm{m}$.

[42-52]. The studies have supported the concept that leachable components of the dental materials are responsible for the cytotoxicity in cell culture. It has been suggested that GICs, which released fluoride in high quantities, were highly cytotoxic to human dental pulp stem cells [53]. A study conducted in mouse lymphoma cells support the idea that the cell membrane was the main target for the toxic agent of the GICs and the damage occurred quickly $[54,55]$. It is in accordance with our findings that show the damage in the first $24 \mathrm{hr}$ and the loss of membrane integrity by calcein AM staining.

When a modification is made in a dental material, it is very important to reevaluate its biological and mechanical characteristics. It has been reported in the literature that the modifications of the powder-liquid ratio of the glass ionomer cements could affect some of the mechanical properties of the materials as well as their resistance to acid erosion [55], that is why in the present study only antibacterial substances were added at $1 \mathrm{wt} \%$ and $2 \mathrm{wt} \%$. In the results, we can see that the addition of antibacterial substances to $1 \mathrm{wt} \%$ or $2 \mathrm{wt} \%$ gives different results for the Vickers microhardness and the average roughness of the surface, which indicates that the materials do not behave in the same way when modifying this powder-liquid ratio.

Various factors such as the manufacture of specimens, the shape of the specimens, and the storage, among others, can influence the mechanical tests, for which it is important to use the methods most accepted by the literature [56]. The international regulations specify that samples must be left in incubation for 24 hours prior to being subjected to physical or mechanical tests as specified in ISO 9917-2: 2010 [57]. In several studies, the mechanical characteristics 


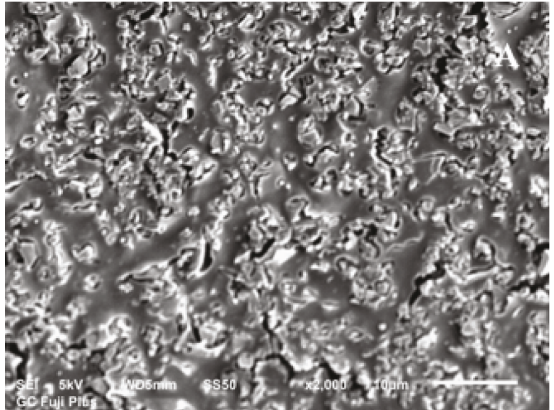

(a)

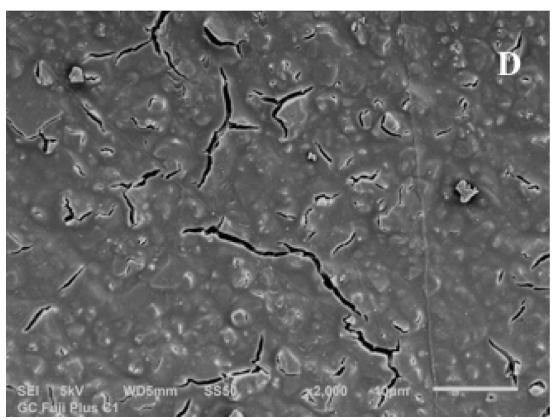

(d)

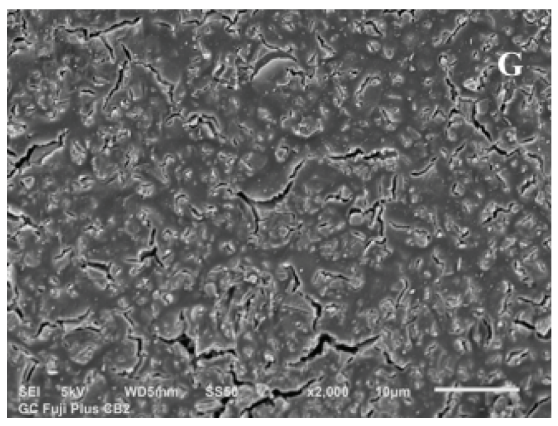

(g)

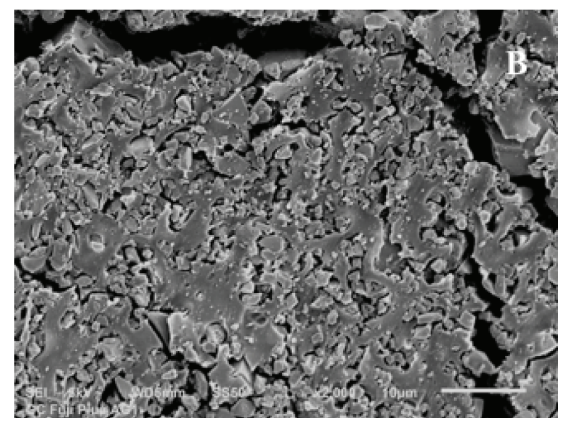

(b)

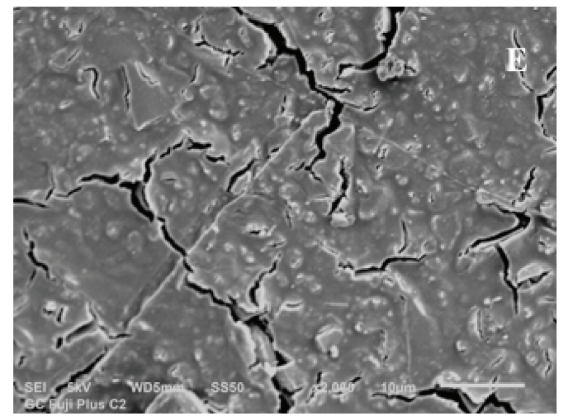

(e)

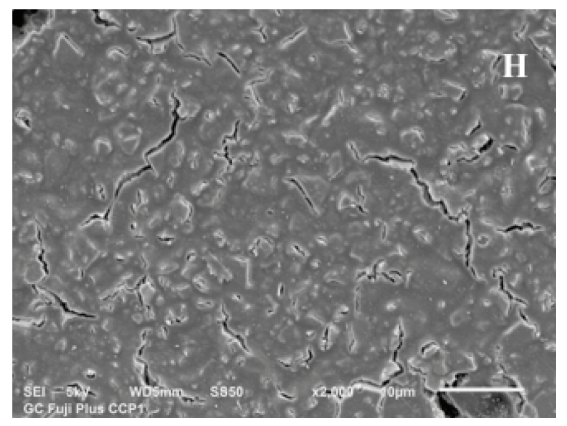

(h)

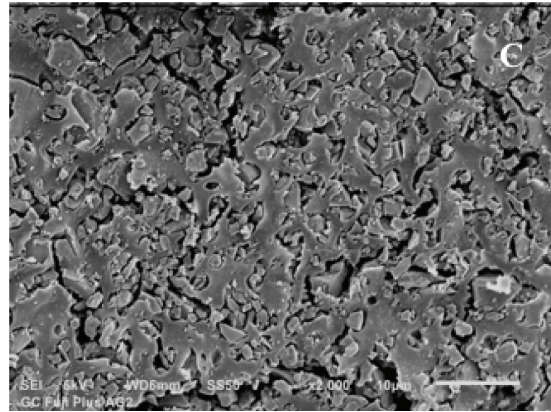

(c)

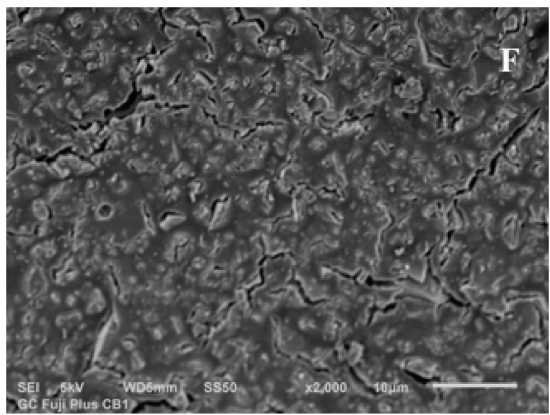

(f)

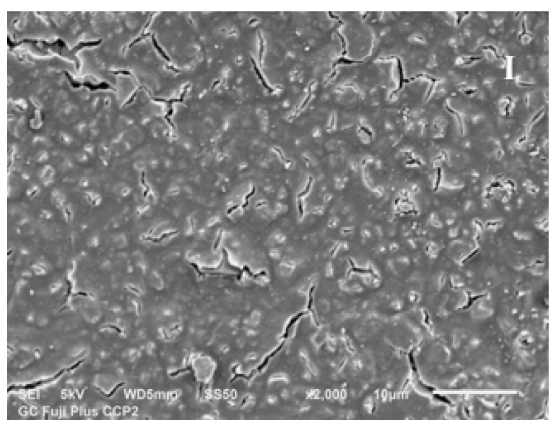

(i)

Figure 6: Scanning electron microscopy micrographs at $\times 2000$ (a) GC Fuji PLUS, (b) GC Fuji PLUS and silver nanoparticles 1 wt\%, (c) GC Fuji PLUS and silver nanoparticles $2 \mathrm{wt} \%$, (d) GC Fuji PLUS and hexadecyltrimethylammonium bromide $1 \mathrm{wt} \%$, (e) GC Fuji PLUS and hexadecyltrimethylammonium bromide $2 \mathrm{wt} \%$, (f) GC Fuji PLUS and benzalkonium chloride 1 wt\%, (g) GC Fuji PLUS and benzalkonium chloride $2 \mathrm{wt} \%$, (h) GC Fuji PLUS and cetylpyridinium chloride $1 \mathrm{wt} \%$, and (i) GC Fuji PLUS and cetylpyridinium chloride $2 \mathrm{wt} \%$. Scale bar: $10 \mu \mathrm{m}$.

of the glass ionomer evaluated after conserving the samples in dry and wet conditions are reported; these studies have found a difference in the behavior of the materials in various conditions [58]. In the present study, samples were preserved in dry conditions but the formation of cracks in the surface prevented having a sufficient firm area to perform the indentations in the Vickers microhardness test and to have an appropriate scanning area for atomic force microscopy. The surface hardness is a test that allows us to have an idea of how the behavior of the materials will be when exposed to occlusal trauma and its relation with the elastic modulus of the material. In the present study, the majority of the modifications decrease the VHN; this result could be related to the modification of the liquid powder proportion of the materials when adding the antibacterial agents, since it is reported that microhardness can be affected by the ratio of glass particles to polyacid. In the current literature, there is no information about the surface roughness or hardness of the control materials. In other RMGIC, different values are reported; for example, de $\mathrm{Ra}$ for Fuji II varies from $0.41 \mu \mathrm{m}, 0.56 \mu \mathrm{m}$, or $1.54 \mu \mathrm{m}$ and the VHN varies from 42.28 VHN, 583.44 VHN, or 739.38 VHN. In the present study, the experimental groups are evaluated in comparison with the control group [59-61].

The roughness of the surface is related to wear and biological outcomes including periodontitis, periodontal disease, and the development of secondary caries due to dent bacterial plaque accumulation. A roughness of the surface greater than $0.2 \mu \mathrm{m}$ allows the accumulation of bacteria on the surface of the material [62]. The micrographs obtained in this study show pores and air voids in the surface, similar with other SEM micrographs of the RMGIC and GIC.

The results of this study show that the modifications reduce the roughness of the surface of the material, which 


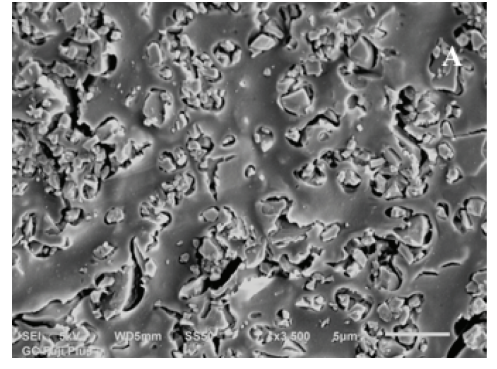

(a)

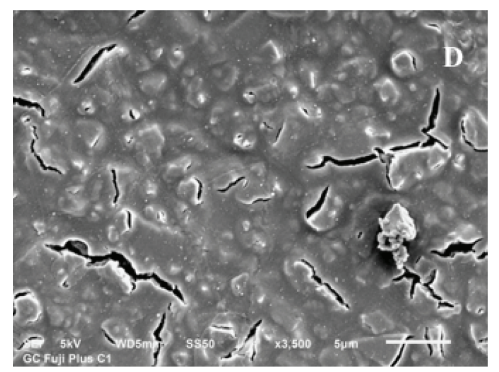

(d)

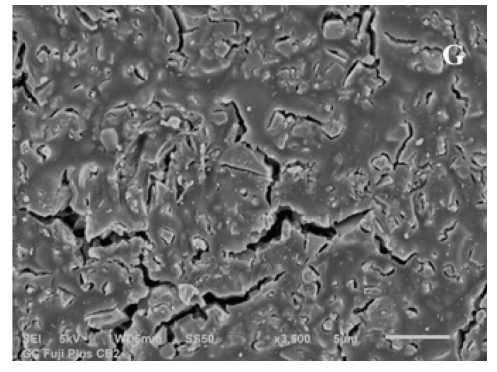

(g)

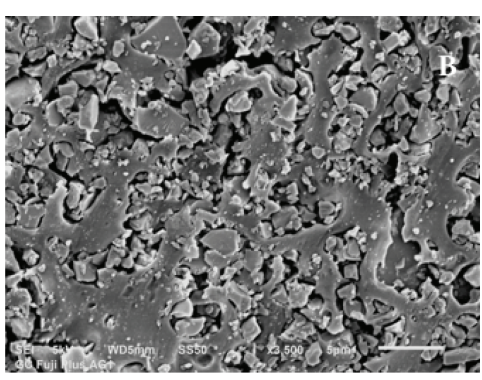

(b)

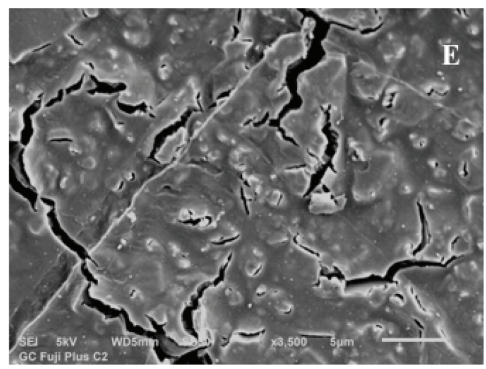

(e)

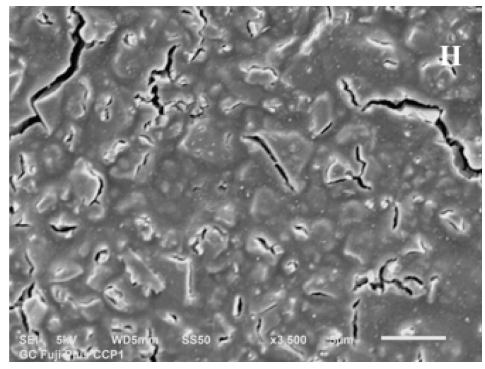

(h)

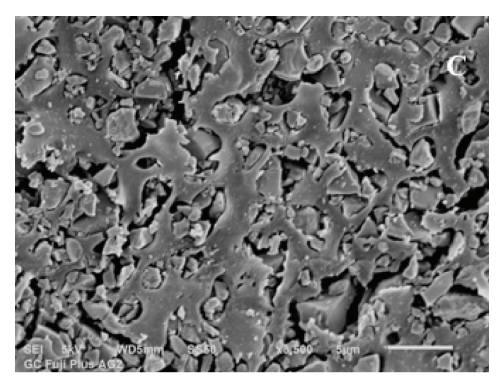

(c)

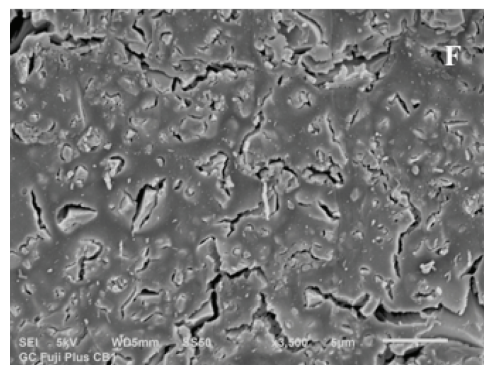

(f)

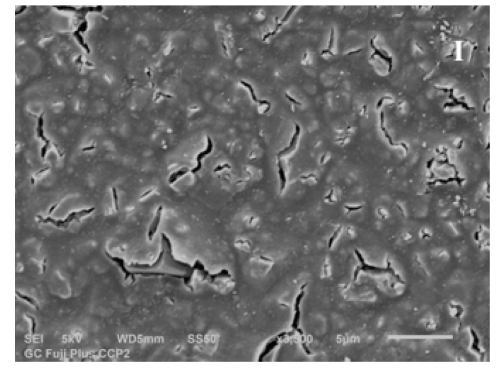

(i)

Figure 7: Scanning electron microscopy micrographs at $\times 3500$ : (a) GC Fuji PLUS, (b) GC Fuji PLUS and silver nanoparticles 1 wt\%, (c) GC Fuji PLUS and silver nanoparticles $2 \mathrm{wt} \%$, (d) GC Fuji PLUS and hexadecyltrimethylammonium bromide 1 wt\%, (e) GC Fuji PLUS and hexadecyltrimethylammonium bromide $2 \mathrm{wt} \%$, (f) GC Fuji PLUS and benzalkonium chloride $1 \mathrm{wt} \%$, (g) GC Fuji PLUS and benzalkonium chloride $2 \mathrm{wt} \%$, (h) GC Fuji PLUS and cetylpyridinium chloride $1 \mathrm{wt} \%$, and (i) GC Fuji PLUS and cetylpyridinium chloride 2 wt $\%$. Scale bar: $5 \mu \mathrm{m}$.

can be a positive aspect in its use in the clinic; in materials modified with QAC, this can be explained by the strong chemical affinity of these compounds with the matrix derived from polyacrylic acid of the RMGICs and in the case of the nanoparticles by the particle size used. It is important to understand the limitations of the in vitro study but also to take into account that they are important indicators of the behavior that we can expect from the materials in their clinical application.

\section{Conclusions}

Based on the results obtained in the present in vitro study, it was concluded that GC Fuji ORTHO and GC Fuji PLUS have high cytotoxicity compared with the medium control group. According with the methodology employed in the present study, only the addition of BC at $2 \%$ in the GC Fuji ORTHO LC reduces the cell viability compared with the control cement without the modification. All the modifications with the exception of one experimental group (GC Fuji PLUS added with 2\% AgNP) decreases the VHN of the RMGICs. The addition of $1 \% \mathrm{CE}$ and $1 \% \mathrm{BC}$ to Gc Fuji ORTHO LC and the addition of $1 \%$ BC to Gc Fuji PLUS increases the $\mathrm{Ra}$ of the RMGICs. The SEM micrographs obtained in this study show that control and experimental groups have very similar surface characteristics. Further in vivo studies are necessary to determine whether these results can be extrapolated to clinical situations.

\section{Data Availability}

The datasets generated during and/or analyzed during the current study are available from the corresponding author on reasonable request.

\section{Conflicts of Interest}

The authors declare that there is no conflict of interest regarding the publication of this paper. 


\section{References}

[1] S. F. Rosenstiel, M. F. Land, and B. J. Crispin, "Dental luting agents: a review of the current literature," The Journal of Prosthetic Dentistry, vol. 80, no. 3, pp. 280-301, 1998.

[2] J. H. Berg, "Glass ionomer cements," Pediatric Dentistry, vol. 24, no. 5, pp. 430-438, 2002.

[3] M. E. I. Gryst and G. J. Mount, "The use of glass ionomer in special needs patients," Australian Dental Journal, vol. 44, no. 4, pp. 268-274, 1999.

[4] S. Cianetti, G. Lombardo, E. Lupatelli et al., "Dental fear/anxiety among children and adolescents. A systematic review," European Journal of Paediatric Dentistry, vol. 18, no. 2, pp. 121-130, 2018.

[5] S. Cianetti, G. Lombardo, E. Lupatelli et al., "Dental caries, parents educational level, family income and dental service attendance among children in Italy," European Journal of Paediatric Dentistry, vol. 18, no. 1, pp. 15-18, 2017.

[6] J. M. Chalmers, "Minimal intervention dentistry: part 2. Strategies for addressing restorative challenges in older patients," Journal of Canadian Dental Association, vol. 72, no. 5, pp. 435-440, 2006.

[7] A. D. Wilson and B. E. Kent, "The glass-ionomer cement, a new translucent dental filling material," Journal of Chemical Technology and Biotechnology, vol. 21, no. 11, p. 313, 1971.

[8] S. K. Sidhu and T. F. Watson, "Resin-modified glass ionomer materials. A status report for the American Journal of Dentistry," American Journal of Dentistry, vol. 8, no. 1, pp. 59-67, 1995.

[9] J. F. McCabe, "Resin-modified glass-ionomers," Biomaterials, vol. 19, no. 6, pp. 521-527, 1998.

[10] B. J. Sanders, R. L. Gregory, K. Moore, and D. R. Avery, “Antibacterial and physical properties of resin modified glassionomers combined with chlorhexidine," Journal of Oral Rehabilitation, vol. 29, no. 6, pp. 553-558, 2002.

[11] A. R. Prabhakar, K. Pattanshetti, and S. Sugandhan, "A comparative study of color stability and fluoride release from glass ionomer cements combined with chlorhexidine," International Journal of Clinical Pediatric Dentistry, vol. 6, no. 1, pp. 26-29, 2013.

[12] A. R. F. de Castilho, C. Duque, T. d. C. Negrini et al., "In vitro and in vivo investigation of the biological and mechanical behaviour of resin-modified glass-ionomer cement containing chlorhexidine," Journal of Dentistry, vol. 41, no. 2, pp. 155163, 2013.

[13] P. W. R. Osinaga, R. H. M. Grande, R. Y. Ballester, M. R. L. Simionato, C. R. M. Delgado Rodrigues, and A. Muench, "Zinc sulfate addition to glass-ionomer based cements: influence on physical and antibacterial properties, zinc and fluoride release," Dental Materials, vol. 19, no. 3, pp. 212-217, 2003.

[14] A. R. F. de Castilho, C. Duque, T. d. C. Negrini et al., "Mechanical and biological characterization of resin-modified glassionomer cement containing doxycycline hyclate," Archives of Oral Biology, vol. 57, no. 2, pp. 131-138, 2012.

[15] T. Tüzüner and T. Ulusu, "Effect of antibacterial agents on the surface hardness of a conventional glass-ionomer cement," Journal of Applied Oral Science, vol. 20, no. 1, pp. 45-49, 2012.

[16] F. M. Korkmaz, T. Tüzüner, O. Baygin, C. K. Buruk, R. Durkan, and B. Bagis, "Antibacterial activity, surface roughness, flexural strength and solubility of conventional luting cements containing chlorhexidine diacetate/cetrimide mixtures," Journal of Prosthetic Dentistry, vol. 110, no. 2, pp. 107-115, 2013.

[17] M. Deepalakshmi, S. Poorni, R. Miglani, I. Rajamani, and S. Ramachandran, "Evaluation of the antibacterial and physical properties of glass ionomer cements containing chlorhexidine and cetrimide: an in-vitro study," Indian Journal of Dental Research, vol. 21, no. 4, pp. 552-556, 2010.

[18] N. Beyth, R. Pilo, and E. I. Weiss, "Antibacterial Activity of Dental Cements Containing Quaternary Ammonium Polyethylenimine Nanoparticles," Journal of Nanomaterials, vol. 2012, Article ID 814763, 6 pages, 2012.

[19] P. C. Siqueira, A. P. R. Magalhaes, W. C. Carvalho-Pires et al., "Cytotoxicity of glass ionomer cements containing silver nanoparticles," Journal of Clinical and Experimental Dentistry, vol. 7, no. 5, pp. e622-e627, 2015.

[20] G. McDonnell and A. D. Russell, "Antiseptics and disinfectants: activity, action and resistance," Clinical Microbiology Reviews, vol. 12, no. 1, pp. 147-179, 1999.

[21] S. B. Lee, R. R. Koepsel, S. W. Morley, K. Matyjaszewski, Y. Sun, and A. J. Russell, "Permanent, nonleaching antibacterial surfaces. 1 . Synthesis by atom transfer radical polymerization," Biomacromolecules, vol. 5, no. 3, pp. 877-882, 2004.

[22] F. Li, Z. G. Chai, M. N. Sun et al., "Anti-biofilm effect of dental adhesive with cationic monomer," Journal of Dental Research, vol. 88, no. 4, pp. 372-376, 2009.

[23] P. Thebault, E. Taffin de Givenchy, R. Levy, Y. Vandenberghe, F. Guittard, and S. Géribaldi, "Preparation and antimicrobial behaviour of quaternary ammonium thiol derivatives able to be grafted on metal surfaces," European Journal of Medicinal Chemistry, vol. 44, no. 2, pp. 717-724, 2009.

[24] N. Beyth, I. Yudovin-Farber, R. Bahir, A. J. Domb, and E. I. Weiss, "Antibacterial activity of dental composites containing quaternary ammonium polyethylenimine nanoparticles against Streptococcus mutans," Biomaterials, vol. 27, no. 21, pp. 3995-4002, 2006.

[25] F. Li, J. Chen, Z. Chai et al., "Effects of a dental adhesive incorporating antibacterial monomer on the growth, adherence and membrane integrity of Streptococcus mutans," Journal of Dentistry, vol. 37, no. 4, pp. 289-296, 2009.

[26] D. Xie, Y. Weng, X. Guo, J. Zhao, R. L. Gregory, and C. Zheng, "Preparation and evaluation of a novel glass-ionomer cement with antibacterial functions," Dental Materials, vol. 27, no. 5, pp. 487-496, 2011

[27] M. G. Botelho, "Inhibitory effects on selected oral bacteria of antibacterial agents incorporated in a glass ionomer cement," Caries Research, vol. 37, no. 2, pp. 108-114, 2003.

[28] M. Rai, A. Yadav, and A. Gade, "Silver nanoparticles as a new generation of antimicrobials," Biotechnology Advances, vol. 27, no. 1, pp. 76-83, 2009.

[29] F. Li, M. D. Weir, J. Chen, and H. H. K. Xu, "Comparison of quaternary ammonium-containing with nano-silvercontaining adhesive in antibacterial properties and cytotoxicity," Dental Materials, vol. 29, no. 4, pp. 450-461, 2013.

[30] S. J. Ahn, S. J. Lee, J. K. Kook, and B. S. Lim, "Experimental antimicrobial orthodontic adhesives using nanofillers and silver nanoparticles," Dental Materials, vol. 25, no. 2, pp. 206-213, 2009.

[31] K. Zhang, L. Cheng, S. Imazato et al., "Effects of dual antibacterial agents MDPB and nano-silver in primer on microcosm biofilm, cytotoxicity and dentine bond properties," Journal of Dentistry, vol. 41, no. 5, pp. 464-474, 2013. 
[32] J. M. Corrêa, M. Mori, H. L. Sanches, A. D. d. Cruz, E. Poiate, and I. A. V. P. Poiate, "Silver nanoparticles in dental biomaterials," International Journal of Biomaterials, vol. 2015, Article ID 485275, 9 pages, 2015.

[33] C. Peskersoy and O. Culha, "Comparative evaluation of mechanical properties of dental nanomaterials," Journal of Nanomaterials, vol. 2017, Article ID 6171578, 8 pages, 2017.

[34] L. F. Espinosa-Cristóbal, G. A. Martínez-Castañón, E. J. Téllez-Déctor, N. Niño-Martínez, N. V. Zavala-Alonso, and J. P. Loyola-Rodríguez, "Adherence inhibition of Streptococcus mutans on dental enamel surface using silver nanoparticles," Materials Science and Engineering: C, vol. 33, no. 4, pp. 2197-2202, 2013.

[35] M. Schmid-Schwap, A. Franz, F. König et al., "Cytotoxicity of four categories of dental cements," Dental Materials, vol. 25, no. 3, pp. 360-368, 2009.

[36] J. Weyermann, D. Lochmann, and A. Zimmer, "A practical note on the use of cytotoxicity assays," International Journal of Pharmaceutics, vol. 288, no. 2, pp. 369-376, 2005.

[37] O. Bussolati, S. Belletti, J. Uggeri et al., "Characterization of apoptotic phenomena induced by treatment with Lasparaginase in NIH3T3 cells," Experimental Cell Research, vol. 220, no. 2, pp. 283-291, 1995.

[38] W. Geurtsen, "Substances released from dental resin composites and glass ionomer cements," European Journal of Oral Sciences, vol. 106, no. 2p2, pp. 687-695, 1998.

[39] K. Nakagawa, M. Saita, T. Ikeda et al., "Biocompatibility of 4META/MMA-TBB resin used as a dental luting agent," The Journal of Prosthetic Dentistry, vol. 114, no. 1, pp. 114-121, 2015.

[40] H. Chadda, S. V. Naveen, S. Mohan, B. K. Satapathy, A. R. Ray, and T. Kamarul, "Cytotoxic evaluation of hydroxyapatitefilled and silica/hydroxyapatite-filled acrylate-based restorative composite resins: an in vitro study," The Journal of Prosthetic Dentistry, vol. 116, no. 1, pp. 129-135, 2016.

[41] T. de Caluwé, C. W. J. Vercruysse, H. A. Declercq, D. Schaubroeck, R. M. H. Verbeeck, and L. C. Martens, "Bioactivity and biocompatibility of two fluoride containing bioactive glasses for dental applications," Dental Materials, vol. 32, no. 11, pp. 1414-1428, 2016.

[42] I. Suciu, C. Varlan, B. Dimitriu et al., "Biocompatibility study of several esthetic dental restorative materials," Romanian Biotechnological Letters, vol. 21, no. 2, pp. 11438-11442, 2016.

[43] D. M. Moreira, J. Oei, H. R. Rawls et al., "A novel antimicrobial orthodontic band cement with in situ-generated silver nanoparticles," Angle Orthodontist, vol. 85, no. 2, pp. 175-183, 2015.

[44] H. E. Ülker, A. I. Erkan, N. Günaydin, F. Kahvecioglu, and M. Ülker, "Comparison of the mechanical and biological properties of self-adhering materials," Journal of Adhesion Science and Technology, vol. 30, no. 10, pp. 1119-1130, 2016.

[45] F. Nikfarjam, K. Beyer, A. König et al., "Influence of biodentine $^{\circledR}$ - a dentine substitute-on collagen type I synthesis in pulp fibroblasts in vitro," PLoS One, vol. 11, no. 12, article e0167633, 2016.

[46] L. Karygianni, S. Proksch, S. Schneider et al., "The effects of various mixing solutions on the biocompatibility of mineral trioxide aggregate," International Endodontic Journal, vol. 49, no. 6, pp. 561-573, 2016.

[47] D. A. Ribeiro, M. E. A. Marques, and D. M. F. Salvadori, "Biocompatibility of glass-ionomer cements using mouse lymphoma cells in vitro," Journal of Oral Rehabilitation, vol. 33, no. 12, pp. 912-917, 2006.

[48] C. Zhang, F. Cui, G. M. Zeng et al., "Quaternary ammonium compounds (QACs): a review on occurrence, fate and toxicity in the environment," Science of the Total Environment, vol. 518-519, pp. 352-362, 2015.

[49] J. J. Antony, P. Sivalingam, and B. Chen, "Toxicological effects of silver nanoparticles," Environmental Toxicology and Pharmacology, vol. 40, no. 3, pp. 729-732, 2015.

[50] S. Tamilselvam, M. J. Divyanand, and P. Neelakantan, "Biocompatibility of a conventional glass ionomer, ceramic reinforced glass ionomer, giomer and resin composite to fibroblasts: in vitro study," Journal of Clinical Pediatric Dentistry, vol. 37, no. 4, pp. 403-406, 2013.

[51] R. Lacerda-Santos, M. I. S. S. de Farias, F. G. de Carvalho et al., "In vivo biocompatibility versus degree of conversion of resin-reinforced cements in different time periods," Microscopy Research and Technique, vol. 77, no. 5, pp. 335340, 2014.

[52] I. A. Rodriguez, C. A. Ferrara, F. Campos-Sanchez, M. Alaminos, J. U. Echevarría, and A. Campos, "An in vitro biocompatibility study of conventional and resin-modified glass ionomer cements," The Journal of Adhesive Dentistry, vol. 15, no. 6, pp. 541-546, 2013.

[53] T. Kanjevac, M. Milovanovic, V. Volarevic et al., "Cytotoxic effects of glass ionomer cements on human dental pulp stem cells correlate with fluoride release," Medicinal Chemistry, vol. 8, no. 1, pp. 40-45, 2012.

[54] A. M. Whitaker and C. J. Hayward, "The characterization of three monkey kidney cell lines," Developments in Biological Standardization, vol. 60, pp. 125-131, 1985.

[55] V. N. Zahra, S. G. Kohen, and R. L. Macchi, "Powder-liquid ratio and properties of two restorative glass ionomer cements," Acta Odontológica Latinoamericana, vol. 24, no. 2, pp. 200204, 2011.

[56] D. C. Smith, "Composition and characteristics of glass ionomer cements," The Journal of the American Dental Association, vol. 120, no. 1, pp. 20-22, 1990.

[57] ISO 9917-2:2010, Dentistry-Water Based Cements - Part 2: Resin-Modified Cements, Geneva, Switzerland, 2010.

[58] M. Chieruzzi, S. Pagano, G. Lombardo et al., "Effect of nanohydroxyapatite, antibiotic, and mucosal defensive agent on the mechanical and thermal properties of glass ionomer cements for special needs patients," Journal of Materials Research, vol. 33, no. 6, pp. 638-649, 2018.

[59] C. Yuan, X. Wang, X. Gao, F. Chen, X. Liang, and D. Li, "Effects of surface properties of polymer-based restorative materials on early adhesion of Streptococcus mutans in vitro," Journal of Dentistry, vol. 54, pp. 33-40, 2016.

[60] C. I. Saveanu, O. Dragos, and H. Chiriac, "Correlation between morphology, structure and composition at the glass ionomer bioadhesive materials," Journal of Optoelectronics and Advanced Materials, vol. 14, no. 9, pp. 826-834, 2012.

[61] O. Bala, H. D. Arisu, I. Yikilgan, S. Arslan, and A. Gullu, "Evaluation of surface roughness and hardness of different glass ionomer cements," European Journal of Dentistry, vol. 6, no. 1, pp. 79-86, 2012.

[62] Z. Arslanoglu, H. Altan, O. Sahin, M. G. Tekin, and M. Adigüzel, "Evaluation of surface properties of four toothcolored restorative materials," Acta Physica Polonica A, vol. 128, no. 2B, pp. B-310-B-313, 2015. 


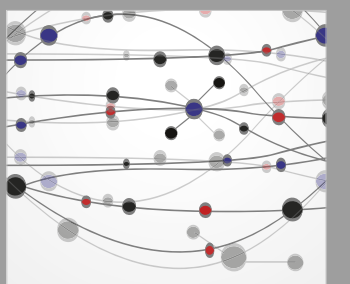

The Scientific World Journal
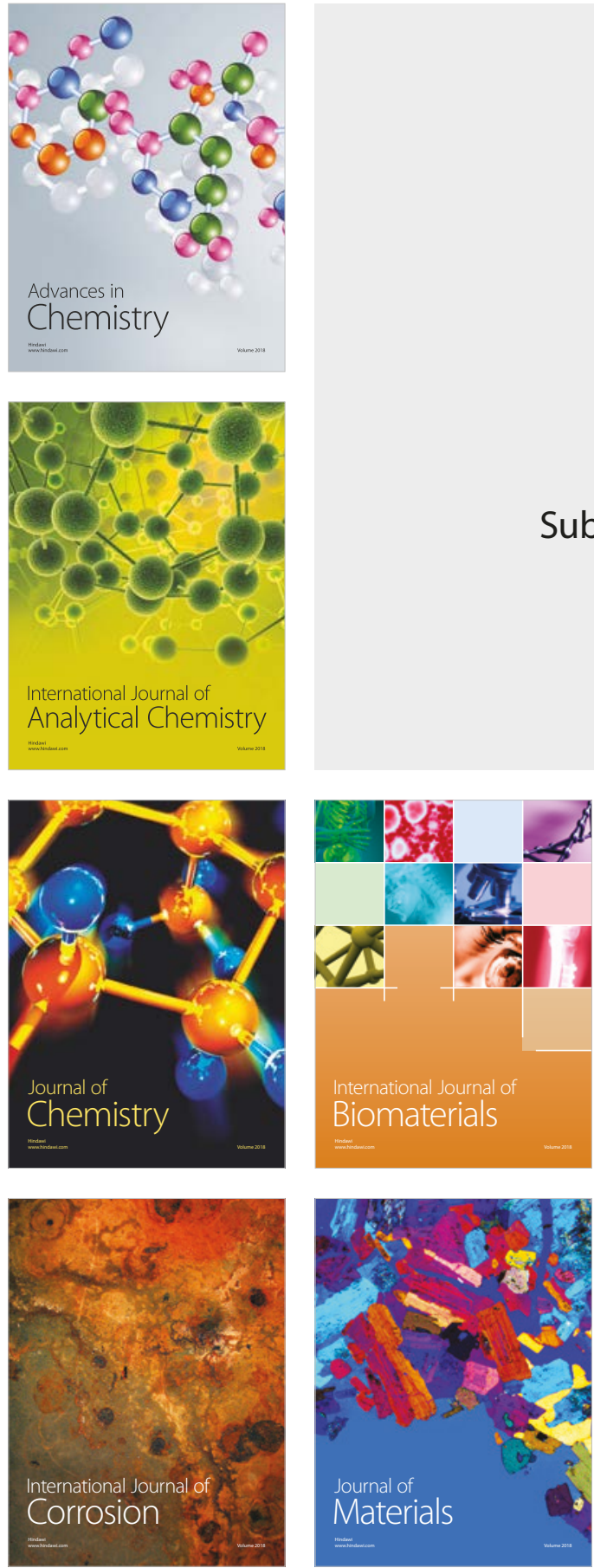

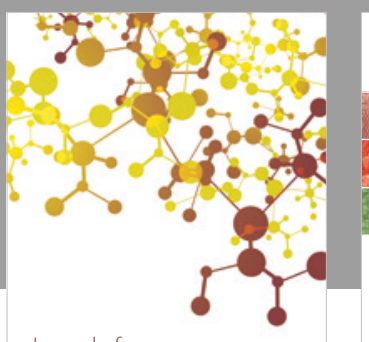

Journal of

Applied Chemistry
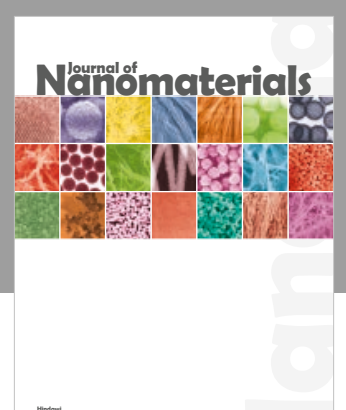

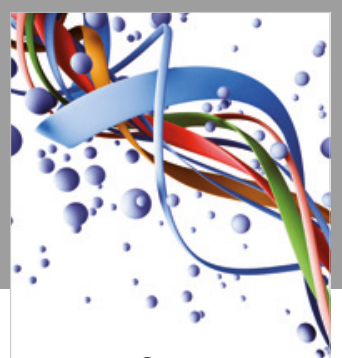

Scientifica

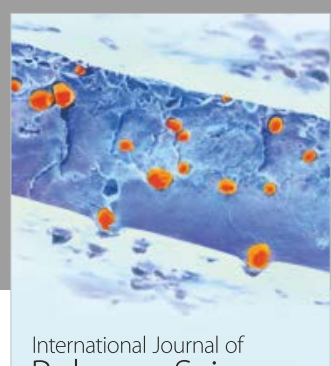

Polymer Science

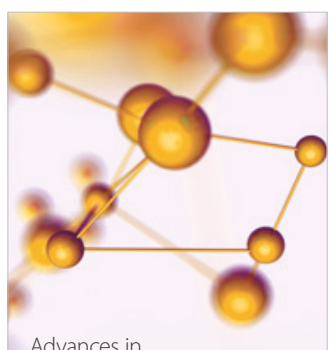

Physical Chemistry
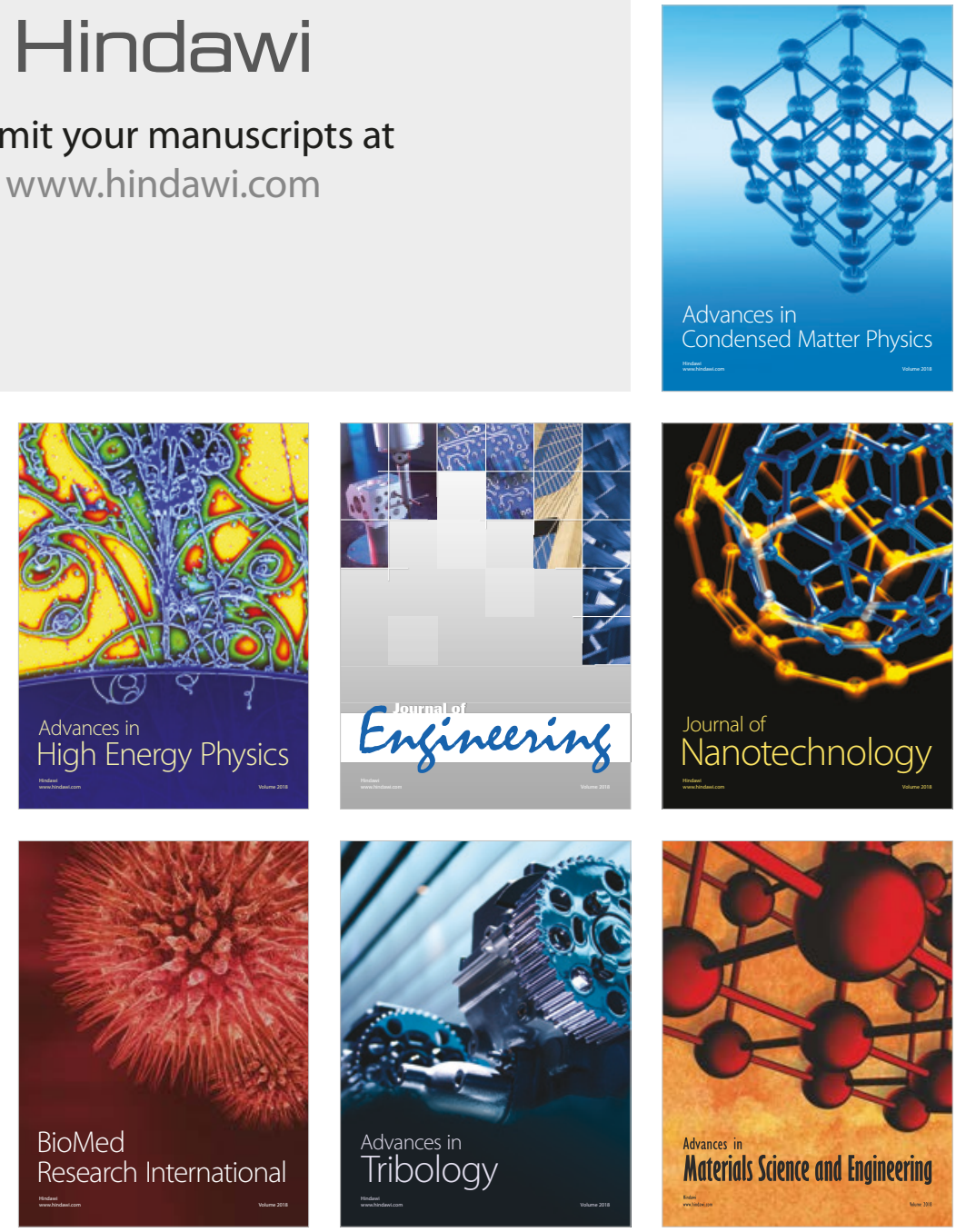